\title{
OVERVIEW OF GRINDING SYSTEMS AND MV DRIVE TECHNOLOGIES IN MINES
}

\author{
Ashok K Wankhede \\ HBNI, BARC, Trombay, \\ Mumbai Maharashtra, India
}

\author{
Dr Archana Sharma \\ BTDG, BARC, Trombay \\ Mumbai, Maharashtra, India
}

\author{
Prof B G Fernandis \\ Dept. of Electrical Engineering, \\ IIT Bombay, Maharashtra, India
}

\begin{abstract}
Mining of ore has become technology driven operation today. The mined ore needs to be processed at site so that further operations are convenient and cost effective and high volumes are processed. Grinding of ore is one of the most important and power intensive operation in mining. In order to process the ore at faster rate, sizes of mills have gone bigger and bigger. While mill diameters have touched 42 feet, at the same time power required has gone upto $38 \mathrm{MW}$ per system. Because of huge processing requirements, mills have migrated from geared to gearless and accordingly changes in mechanical systems, drive motors and power converter technologies have thrown a bigger challenge. Scaling up the equipment also has major requirement of robust mechanical design to reduce maintenance and ensure reliable operation.
\end{abstract}

This paper focuses on overview of various grinding systems, drive and converter technologies and other aspects like design, operation and maintenance. Comprehensive literature survey conducted and systems which are being used today are compared with respect to cost, efficiency and drawbacks. Also possible advanced technologies with respect to improvement in Drive is also suggested.

Keywords-Gearless Mill Drives, Semi Autogeneous, cycloconverters, multilevel

\section{INTRODUCTION}

Ore Grinding is commonly done at Mine site to eliminate transportation cost, waste management and making product cost effective. Large Grinding mills are used for Grinding with Induction and synchronous motors of max 38 MW capacity but for low speed. The reliable operation of the drive is essential to prevent business interruption loss which can be huge. Presently Geared and Gearless Grinding mills are in use for the purpose. Geared mills use Induction motors and Synchronous motors but there is a limitation on gears for power greater than $18 \mathrm{MW}$, moreover gears encounter maintenance problems. Gearless drives are being used where motors are coupled directly to Mill cylinder. Systems with synchronous motors upto $38 \mathrm{MW}$ driven by cyclo-converters are reported. Because of large size of mill cylinder, operating speed is in the range 0-10 RPM. Cyclo-converter inherently though efficient and reliable, has problems related to harmonics and inter-harmonics. This calls for huge passive filter banks which not only consumes power but also occupies space. In addition, it creates problems of resonances which affect the system reliability.

Synchronous motors are ideal for this application because of unity power factor and good efficiency but it suffers few problems like complex construction and effective starting. Options are available in terms of induction motor and PM motor which do not have these issues. For power converter, modular multilevel converters are becoming viable option due to availability of power devices, upcoming $\mathrm{SiC}$ devices and possibility of fault tolerant operation.

\section{ORE PROCESSING SYSTEMS IN MINES}

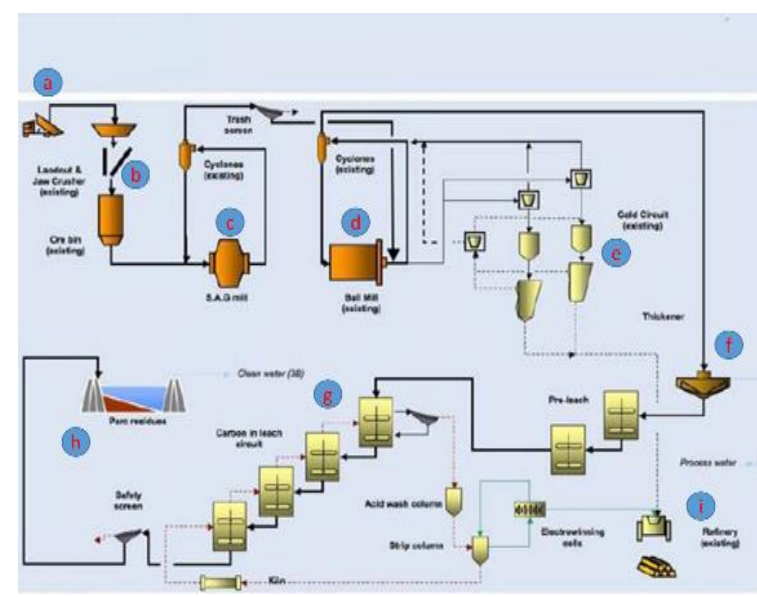

Fig 2.1. Schematic of Ore processing in Mining Circuit [ABB]

Main stages in ore processing are; Size reduction of ore material, crushing and grinding. Fig 2.1 shows the processing steps in typical mining operations. Ore received from mine is brought from (a) for jaw crushing at (b). Then it is fed to SAG mill shown at (c) which is further passed to ball mill after achieving desired size reduction shown at (d). After grinding operation is completed ore undergoes further processing as shown from (e) to (h) to obtain final product which is gold in this case. 


\section{PRINCIPLE OF OPERATION OF GRINDING [1]}

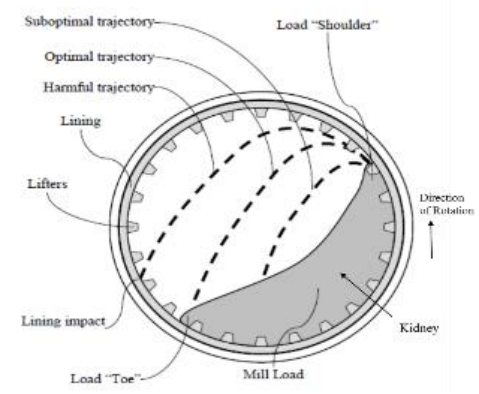

Fig 3.1. Operation of Grinding mill [1]

Fig 3.1 shows the cross section of grinding mill having internal steel liners with lifters for lifting the load. The cylinder is filled with ore and set under rotation anticlockwise direction with the help of drive motor. The speed of rotation is very low 0-10 RPM decided by cylinder diameter and properties of mined ore inside the cylinder etc. While under rotation, the load builds a kidney form as shown. When charge climbs upwards, it tends to fall down under gravity resulting into crushing operation. The weight and speed of rotation decides the centrifugal force and various trajectories as shown. The trajectory is set by adjusting speed of the cylinder to optimum value so that mill operates without any direct impact between charge, liners and lifters thereby avoiding damage. The trajectory impacting at the load toe gives optimum resulting into most effective grinding by steel balls inside the mill while in operation.

For higher throughput, large diameter mills are being employed to use this impacting effect. The movement of the load depends strongly on several operating variables like geometry, viscosity, ore size-distribution and rotational speed. In addition, the wear and tear of the lifters also plays a role because its geometry changes with time. There are also harmful effects because of the ball trajectories impacting in the lifters such as energy loss and accelerated steel ball wear etc. jeopardizing the life of lifters and affecting the availability of the mill. That is why variable speed is needed for high power mills so that perfect trajectories are manipulated. The useful range of operation speed is around $75 \%$ and $80 \%$ of the critical speed. The critical speed is defined as the speed at which a steel ball remains at the shell of the mill without falling when the centrifugal force equals its weight and is given by [1]:

$$
w=\sqrt{\frac{2 g}{(D-d)}} \quad \begin{aligned}
& \text { where, } \mathrm{g}=9.81 \mathrm{~m} / \mathrm{s}^{2}, \\
& \mathrm{D}=\text { internal mill diameter } \\
& \mathrm{d}=\text { diameter of steel balls } \\
& \mathrm{w}=\text { critical speed }
\end{aligned}
$$

Practically, $\mathrm{D}>>\mathrm{d}$ hence, $\mathrm{d}$ can be ignored. If $\mathrm{D}$ in meters, Critical Speed $\mathrm{N}_{\mathrm{c}}$ in RPM is expressed as,

$$
N_{C}=\frac{42.2}{\sqrt{D}}[\mathrm{rpm}]
$$

For example, a typical mill with an internal diameter of 11 meters will have a critical speed of 12.72 RPM. Nominal speed will be $77 \%$ of the critical speed and in this case operating speed is 9.8 RPM. The bigger the diameter, the lower the nominal speed of rotation.

\section{SEMI-AUTOGENOUS (SAG) AND AUTOGENOUS (AG) MILLS [1].}

In both methods SAG and AG mills, crushing and grinding functions are combined. SAG mill is usually used to grind large pieces into small pieces, especially for the preprocessing of grinding circuits, thus also known as primary stage grinding machine. SAG mill crush/grind ores through impact, attrition and abrasion forces. SAG mill is a selfgrinding machine which uses the crushed material inside the cylinder as the grinding medium. The material constantly impacts and grinding to gradually pulverize. Sometimes, in order to improve the processing capacity of the mill, a small amount of steel balls (about 5.0 inch dia.) are added appropriately, usually occupying $2-3 \%$ of the volume of the mill. In practice, for a given ore and equal processing conditions, the AG milling has a finer grind than SAG mills. AG mills are common in the primary processing unit for the major large grinding circuits in the mining field which separates out some precious metals, like gold and silver.

\section{Advantages of SAG Mills:}

1) High processing capacity makes product cost effective.

2) Grinds multiple types of ore, reduces the complexity of maintenance and coordination.

3) Compared with the traditional tumbling mill, AG mill reduces the consumption of lining plates and grinding media, thus have a lower operation cost.

4) The self-grinding machine can grind the material to 0.074 $\mathrm{mm}$ in one time, and its content accounts for $20 \%$ to $50 \%$ of the total product. Grinding ratio can reach 4000 to 5000 , which is more than ten times higher than the ball or rod mill.

\section{TECHNICAL REQUIREMENTS [3]}

Modern grinding mill drives used in copper, gold, and cement industries employ Medium voltage motors with power electronic drives. The main requirements are as follows:

1) Drive with minimum $120 \%$ starting torque without affecting the distribution network.

2) Operation of full system in harsh concentrator environment with wet grinding and high altitudes, commonly > $2000 \mathrm{~m}$ (6000 ft) above mean sea level. 


\section{International Journal of Engineering Applied Sciences and Technology, 2021 \\ Vol. 6, Issue 4, ISSN No. 2455-2143, Pages 171-194 \\ Published Online August 2021 in IJEAST (http://www.ijeast.com)}

3) Low supply frequency, because large diameter grinding mills must rotate at and variable low speeds in the range ranging from 0 to 10 RPM.

4) High reliability and availability to keep process continuity, low business interruption loss (BIL). Estimation shows in a typical Gold mine BIL is of the order of $\$ 7.0$ million per day.

5) Full output frequency and voltage control with fourquadrant operation capability.

6) Frozen Charge detection and management:

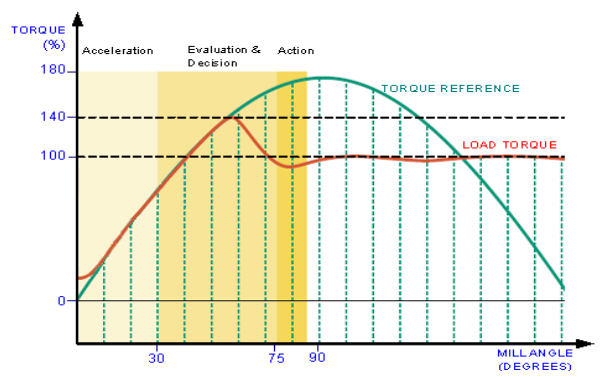

Fig 5.1. Frozen Charge Detection [4]

At standstill, the material inside the mill tends to solidify and stick to the mill shell. This is called frozen charge and could happen even within minutes, depending on the type of material processed. The detection of frozen charge is of significant importance in order to avoid major damage to the mill shell, bearings and liners. As the loaded mill starts up, as shown in the Fig 5.1, the control system evaluates torque build up between $30^{\circ}$ to $75^{\circ}$ ensuring that appropriate decisions are taken before a frozen charge can drop. If the load torque (red) drops within $140 \%$ the system known to be behaving healthy otherwise a frozen charge is detected and fast shutdown is initiated.

7) Inching, Creeping and Positioning:

a) Inching or creeping operation is required to avoid the occurrence of frozen charges, which ensures the charge is loose.

b) Inching is used to position the mill for maintenance work such as liner changes.

8) Power sharing between drives and gears.

When dual pinion drives are used for drum operation, often two drives are employed with gear to operate in parallel, drive should be able to share the load equally.

9) Taking care of Network Voltage Problems.

The drive system used must actively support network in case of voltage dips by reducing the power drawn and thus not further contributing to the collapse of the network. Hence enabling the network to fast recovery. To fulfill all above mentioned requirements, employing reliable motor and power converter is a challenging job. Because of huge processing requirements the mills above 32 feet diameters require power converter systems above $30 \mathrm{MW}$ with low speed (0-10 RPM).

10) Mechanical system design Requirements.

a) In case of short circuit fault, circulation of very large currents through the stator winding of the machine originates huge forces. The structure of the stator, its winding design and the foundation must be designed to resist the forces safely.

b) Isolation failure of stator windings due to wet moisture could be one of the issues. Development of intelligent isolation surveillance may be considered to solve this issue.

c) Vibrations and deflections due to asymmetrical air gap between the motor stator and the rotor: Bigger machines are distributed systems with several degrees of freedom. Electromagnetic linear and non-linear excitation forces may be produced under failure conditions. Deformation modes and force distribution along the poles of the rotor should be carefully analyzed during design stage.

\section{TYPICAL MILL DRIVE SYSTEM \& COMPONENTS}

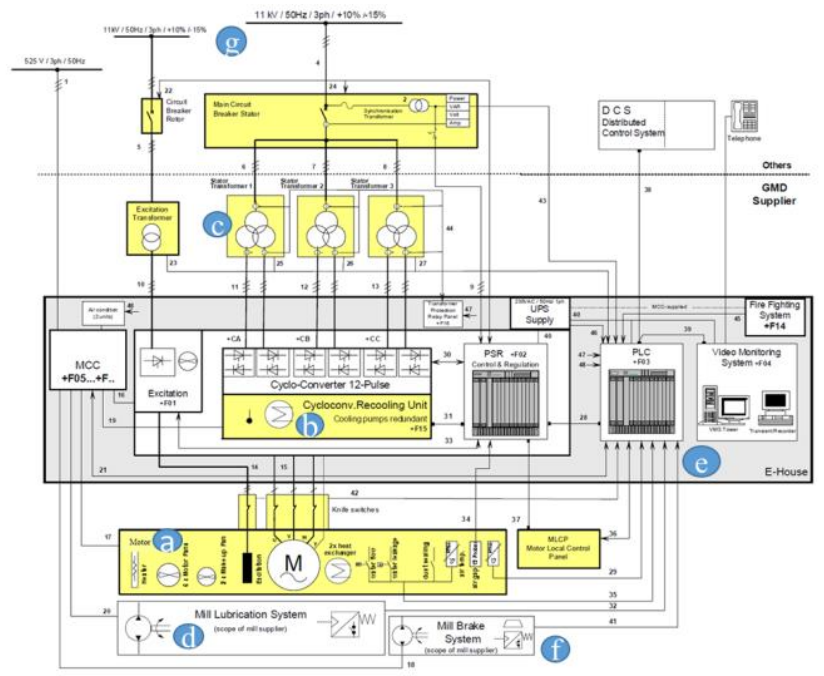

Fig 6.1. Schematic of Typical Mill Drive system components [30],[4]

The schematic diagram of Typical Mill Drive system in a mine is shown in Fig 6.1. The major components of conventional drive system are as follows.

1. Driven equipment (mill, conveyor, slurry pump...) coupled with motor, components altering the speed (gearboxes, girth gear/pinion shown in fig 1.2 as (a)).

2. A variable-speed drive (VSD) or cyclo-converter $(\mathrm{CCV})$ to utilize the possibility of speed variation during operation shown as (b).

3. Input voltage step down and isolation transformers for feeding power to converter shown as (c). 


\section{International Journal of Engineering Applied Sciences and Technology, 2021 \\ Vol. 6, Issue 4, ISSN No. 2455-2143, Pages 171-194 \\ Published Online August 2021 in IJEAST (http://www.ijeast.com)}

4. Mill lubrication system shown as (d).

5. Control, regulation and monitoring systems as (e).

6. Mill brake system used to control stoppage of mill drum as and when required shown as (f).

7. The electrical supply system (cables, switchgear, transformers, protection equipment) shown as (g).

\section{GRINDING MILL SOLUTIONS [4]}

The full range of mills and power is shown in Fig 7.1. The central driven mill solution is found on the lower power range of the mills due to the high torque that has to be transmitted to the mill.

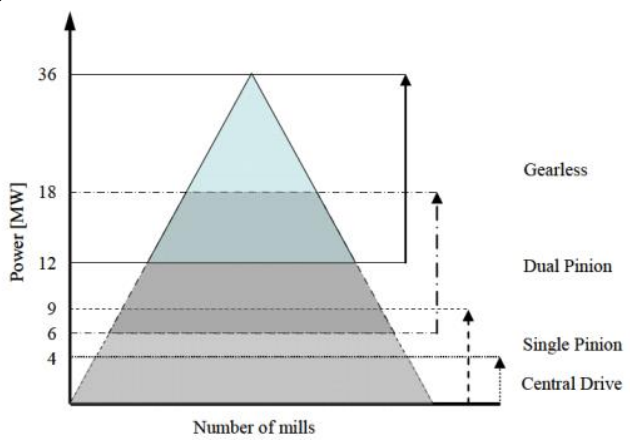

Fig 7.1 Typical mechanical mill configurations [4]

Depending on the power required to turn the mill, different configurations of the mechanical set up are possible. The maximum torque transmission is defined and limited by the mechanics. Single pinion solution is restricted to approximately $9 \mathrm{MW}$ power. Above this power a dual pinion configuration is required, this also implies that mills bigger than $18 \mathrm{MW}$ can only be driven by gearless mill drive (GMDs) [4]. The GMD is covering the upper power range of the mills. The torque is transmitted to the mill directly through the magnetic field in the air gap of the motor, eliminating the gear reducer.

Several factors such as process, mechanical, electrical and cost considerations must be taken into account while selecting the mill system. When determining the mill size and the drive type the required process power needs to be calculated based on design process specific energy ( $\mathrm{kWh} / \mathrm{ton}$ ), plant size (tons/day) and total milling process power. The required process power is divided into circuits and numbers of mills within a circuit, followed by the selection of the mill sizes to fulfil the requirements. The optimal drive type can only be selected after determining the mill size, need for variable speed and the characteristics of the electrical system of the plant. The question what derive system is optimal for SAG and ball mills is project specific and depends on the plant layout and the design of the grinding circuit.

For drives systems comparison the main criteria are:
1. Operating characteristics (fixed or variable speed, starting behavior, interaction with network, harmonic distortion).

2. Maintenance aspects (reliability, wearing parts, downtime) and

3. Cost issues (capital expenditure, power factor and drive efficiency impacting energy cost, maintenance).

In addition, drive systems show differences in other design and operational issues such as inching and creeping, load sharing (if dual pinion drives are used), frozen charge protection and space requirement.

\subsection{Geared mills (Single and Dual Pinion Mills)}

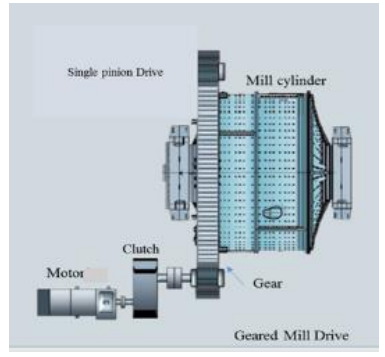

a) Single pinion drive schematic

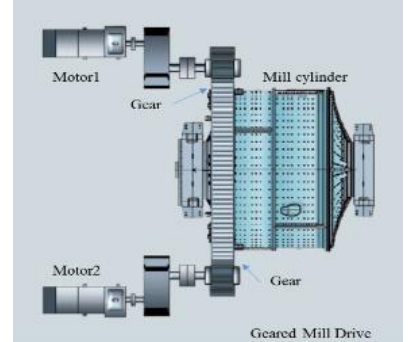

b) Double pinion drive schematic
Fig 7.2. Schematic of Typical Geared Mill Drive system [19]

A schematic of Geared drive is shown in Figure 7.2. System shows single and dual pinion gear coupling to Mill drum with single and double parallel motors respectively. Single and dual pinion configurations can be powered by low speed synchronous motors (approx. 160-200 rpm) connected directly to the pinions driving the ring gear or by high speed asynchronous motors (approx. 750-1500 rpm) that require a reducer between the pinions and the motors.

Today, the maximum power capacity per pinion is less than 10 MW. This could only be increased by improving the design of the ring gear set, such as ring gear hardness, face width or centre distance. Gearboxes for high power and high torque are still a major source for downtimes caused by drive systems. Ring gears and gearboxes usually needs alignment and regular service for operation. Especially for dual pinion drive system the alignment needs to be done with care. Sophisticated methods such as infrared alignment techniques help to make the proper adjustments.

Misalignment between motor and pinion is a major reason for wear in a clutch. However, the drive train not only has to be aligned statically but it also must be checked dynamically when running with a loaded mill. It is required to monitor continuously the pinion tooth mesh with infrared sensors to detect the development of a meshing error and to avoid excessive clutch and gear wear. A major cause for concern in 


\section{International Journal of Engineering Applied Sciences and Technology, 2021 \\ Vol. 6, Issue 4, ISSN No. 2455-2143, Pages 171-194 \\ Published Online August 2021 in IJEAST (http://www.ijeast.com)}

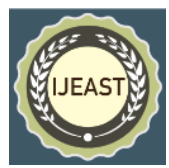

alignment occurs with a mill designed for operation in both directions of rotation. With a single pinion drive, the location of the pinion is such that the pinion tooth is lifting the girth gear and the pinion therefore presses down onto its bearings. If the rotation is reversed, the pinion tooth is now pushing down on the girth gear and the pinion is pushing upwards on its bearings. As a result, the pinion will lift upwards by the amount of clearance designed into the pinion bearings. This may result into increase in wear in clutch. Also by reversing rotation, the axial centreline of the mill will shift as the centre of gravity of the charge moves from one side of centre to the other.

\subsubsection{Drive system for Single and Dual Pinion Mills}

In case of a high speed solution, AC induction motor and for low speed solution a brushless synchronous motor are fed by VSI drive. This drive is connected via a transformer to the medium voltage distribution system. The mills are typically single quadrant application. Some are designed for running in both directions. Depending on the mill power 12 or 24 pulse diode configurations are used. In case of a dual pinion mill a multi-drive configuration, with a common supply unit and two inverter units provide a compact solution.

\subsubsection{The High Speed Motor Solution}

1) Squirrel cage induction motors

These are the most common motors used in the industry due to their versatility, reliability and simplicity and less maintenance. Typically, 6 to 8 pole induction machine driven by $50 \mathrm{~Hz}$ is used to turn the mill. The motors are generally forced cooled which allows running the motor at very low speed (about $5 \%$ of nominal speed) for service mode. Automatic positioning for liner changes and creeping for visual inspection can be performed with the main drive without the need of additional equipment.

Depending on the environment, air cooled motors or water cooled motors which are totally enclosed are used for powers up to $9 \mathrm{MW}$. The advantage of a totally enclosed motor is that the cooling air inside the motor is not affected by the external dusty environment. These motors are equipped with flange mounted bearings installed on the end shields of the motors. To prevent bearing damage from circulating currents, both bearings and case are electrically insulated. The shaft is grounded to avoid static charges of the stator.

\section{2) Slip Ring Motors}

Slip ring motors are high speed fixed speed drives (typically 6 or 8 pole motors) that are usually used for smaller mills. They offer a low capital expenditure solution compared with other drive systems. These motors are started with a starting resistor (oil starters with stepping resistors or liquid starters). Based on the resistor characteristics a relatively smooth start is possible. This drive system is rather robust against voltage dips. However, the power factor is typically not very high and gets worse at part load conditions. Thus, often power factor compensation is installed individually for each slip ring motor.
Furthermore, a separate device is required for inching and creeping. Dual high speed motors can be used to drive through gearboxes to dual pinions. Load sharing is inherently possible but not very accurate. This can lead to load swings between the two motors and result in accelerated gear wear. To overcome these conditions, a permanent slip resistor may be installed between the two rotors. This will improve the load share capability, but at the expense of the drive efficiency (up to $1.5 \%$ reduction).

\subsubsection{Low Speed Motor Solution}

Due to the high torque required by the mill, low speed motors are generally synchronous machines. The mill is a low dynamic system therefore a brushless synchronous machine is best suited for this application. Brushless synchronous motors have no wearing parts, and the $\mathrm{AC} / \mathrm{AC}$ excitation power is kept small. The drive provides the supply and the excitation control as well as the necessary protection. The brushless exciter is a separate AC generator mounted on the motor shaft. For these high torque low speed motors, efficient cooling is required. The choice is between water cooled totally enclosed motors or open machines weather protected type II enclosure and filter air inlet. In addition to their high torque capability, synchronous motors offer a wide field weakening range. This allows the design of motors with nominal frequency below the network frequency. The low speed solution motor used with the drive has a nominal frequency varying from 10-20 Hz. This means a machine with 8-12 poles can be used instead of the big $30-40$ pole machine required by a fixed speed solution having the same torque output.

The main benefits of the low speed motor solution with only 8 to 12 poles, beside the lower capital cost compared to the traditional low speed motors with 30 to 40 poles, is the compactness of the motor. Less weight, smaller dimensions and therefore less critical foundation design for installation Depending on the power, flange mounted sleeve bearings mounted on the end shields of the motor, or pedestal mounted sleeve bearings, are provided. The motors with integral pedestal bearings are easy to mount and align as motors with flange mounted bearings. Here also the bearings are both electrically insulated and the shaft is grounded.

\section{Slip Energy Recovery Drives.}

These drive systems use slip ring motors and are started similarly using starting resistors, thereby limiting the inrush current. To adjust the speed, the slip resistance needs to be changed accordingly. This can be achieved by inserting resistance in the rotor circuit and dissipating this energy into the starting resistors. This solution is very inefficient, so slip energy is converted to direct current, inverted to the frequency of the power system feeding the motor, and then fed back into the power system through a step-up transformer. The switchover to the slip energy recovery system can be done anywhere between 50 and $100 \%$ of nominal speed. 


\section{International Journal of Engineering Applied Sciences and Technology, 2021 \\ Vol. 6, Issue 4, ISSN No. 2455-2143, Pages 171-194 \\ Published Online August 2021 in IJEAST (http://www.ijeast.com)}

In this solution the speed range is smaller than of frequency converter drives, frozen charge protection is not possible and a separate inching drive is required. In reducing the speed of the slip ring motor, the slip energy recovery equipment will generate frequencies at multiples of 6 times the slip frequency, depending on the number of pulses built into the equipment. Because of these excitation frequencies there is a high probability that certain speeds in the operating range of the mill (possible resonance frequencies) will need to be blocked and it is not possible to operate within this particular speed range.

The main reason in the past for using slip energy recovery drives was capital expenditure. However, the use of these drive systems has very much decreased during the last decade because frequency converters have become more and more cost effective and need less maintenance.

\subsection{Gearless Mills (GMDs)}

The principle idea behind a gearless drive system is to reduce the number of components and diversity of parts. Fig 7.3 shows the general scheme of a mill with gearless motor drive and the rotor poles of the machine are bolted to the mill.

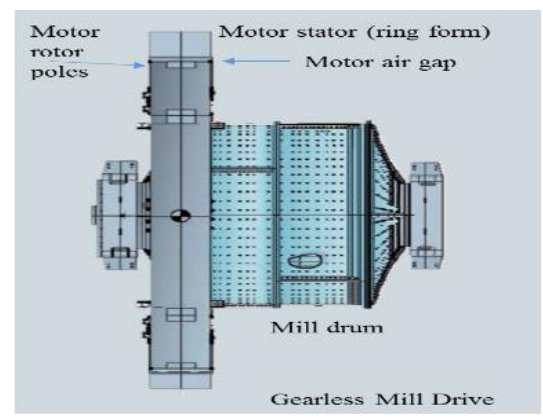

Fig 7.3. Schematic of Typical Gearless Mill Drive system [19]

There is no gear, because the electromagnetic torque is generated directly to the mill. The stator has a ring form, giving the alternative name "ring motor" and is wrappedaround the mill drum. Typical value of the air gap between the stator and the rotor is in the range of $15-20 \mathrm{~mm},+/-3 \mathrm{~mm}$. The motor is run at low speed (0-10 RPM) with variable voltage variable frequency converter in order to regulate the torque and operating speed of the mill. A GMD up to 38MW for 42' ball mills are in production which are suitable for installationat 4600 masl (mean sea level).

\subsubsection{Drive system for Gearless Mills (GMD)}

GMD has ring motor shown in Fig 7.3, wrapped to the outside body of mill cylinder. The cylinder being large diameter (42 feet) motor has to be designed and manufactured for assembly in sections and assembled at site. Large diameter motors have advantage of very large torque as it is proportional to square of diameter. Because of huge power requirements ( > $32 \mathrm{MW}$ ) motor needs to be very efficient in order to minimise power loss and cooling requirements. Keeping this in mind motor should have good power factor and good efficiency. Since motor is a part of rotating mill cylinder which works at low speed (0-10 RPM) it is of direct drive type without any gear. So the desired torque is obtained at low speed and at the time of starting also. In the category of fulfilling requirements, qualified candidates are Induction motor, Synchronous motor and PM motor which is under development at various places.

\subsubsection{Induction motors vs Synchronous Motors [52]}

1) Induction motors have higher currents for the same power levels due to lower efficiency and lower power factor (PF) than Synchronous Motors (SMs). This gap becomes wider with increased pole-pair construction and lower base speeds. SMs operate with higher efficiency, lower currents due to high $\mathrm{PF}$, and have usable low-speed torque characteristics with a VFD. When operated direct on line, the leading PFs provided by SMs offer reactive power that compensates for the reactive power used in other parts of a plant.

2) The induction motor PF depends largely on the base speed or the number of poles in the motor design. For example, in a 5,000-hp, 20-pole SM design, the current can be 585 Amps while an induction motor at the same base speed and power requires $820 \mathrm{Amps}$, a $40 \%$ increase due to extra reactive power used with a lower PF in the induction motor. This increases the cooling requirements as copper losses gets increased significantly in Induction Motor.

3) In induction motors the stator constantly supplies a certain amount of magnetizing current to maintain the magnetic flux, resulting in a lagging motor $\mathrm{PF}$ at all operating conditions. On the other hand, synchronous motor offers an extra freedom of motor field current control and hence its operating PF can be adjusted by the drive to leading, unity or lagging as the system operation prefers.

4) Exciter types in Synchronous Motor.

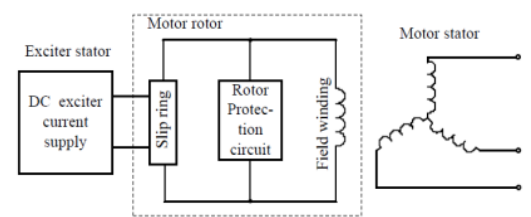

(a) Brush-type exciter

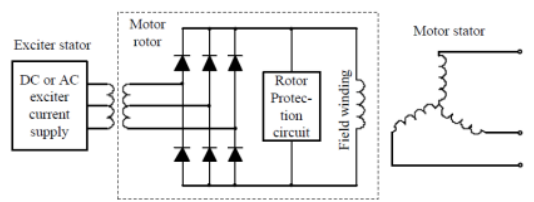

(b) DC or AC brushless exciter

Fig 7.4 Synchronous motor with brush or brushless exciter [5]

Synchronous motors (SMs) require an external DC supply to power the rotor field winding, and can be classified into brush- 


\section{International Journal of Engineering Applied Sciences and Technology, 2021 \\ Vol. 6, Issue 4, ISSN No. 2455-2143, Pages 171-194 \\ Published Online August 2021 in IJEAST (http://www.ijeast.com)}

type or brushless-type based on the exciter structure. Both circuits are shown in fig 7.4. A brush-type synchronous motor is fitted with a static exciter where the current is provided to the rotor through slip rings and brushes. A brushless type synchronous motor is supplied by a rotating exciter. The exciter stator current, either in AC or DC form, is transferred to the rotor through the rotating transformer. The $\mathrm{AC}$ current induced in the rotor is then rectified to a DC current to supply the field winding. In a DC-brushless synchronous motor, the induced voltage in the rotor is proportional to the rotor speed, assuming a constant DC supply in the exciter stator. When the rotor is at standstill, there is no field current supplied to the rotor and therefore, the starting torque capability is much more limited as compared to brush-type or AC-brushless-type of synchronous motor where constant torque load can be supported with position sensor feedback. As the motor speeds up, the voltage induced in the exciter rotor winding increases and thus the DC-brushless motor can support high load torque in the medium to high speed range.

1) Gearboxes needed for higher-speed induction motors typically have losses in the range of $0.5-0.8 \%$ per pair of gears. In addition, maintenance associated with bearings, gears, and lubricants is avoided. Clutches are often used when starting SMs due to the low starting torques associated with across line and early line commutation (LCI) control. Clutches allowed the SM to reach full or near top speed before applying load. With VFDs now using the advanced controls and encoders providing position feedback, starting torques can easily be handled without the use of clutches. With a 100:1 speed range, inching equipment for positioning or maintenance is also eliminated.

2) The ring-motor is a low speed synchronous motor fed by a cyclo-converter. Depending upon the mill speed, the number of rotor poles will be selected. In general, the bigger the mill diameter is, the lower are the mill operating and critical speeds and the higher are the number of rotor poles. It has to be noted that the number of pole units will impact, like with any motor, the motor efficiency. Since the gearless mill drive is typically by far the largest power consumer in a concentrator plant, the number of pole units should be kept to the minimum. The pole number varies typically from 48 for very small ball mills to 76 poles for the largest GMD motors.

Broad comparison of Induction and Synchronous motors is given in Table7.1.

Table 7.1

Characteristics comparison

of Synchronous \& Induction Motor

\begin{tabular}{|c|c|c|c|}
\hline S.N. & Characteristics & Induction Motors & Synchronous Motors \\
\hline 1 & Complexity & Simple design & Complex \\
\hline 2 & Self-starting & Generally yes & Generally no \\
\hline 3 & Power-Density & Average & High \\
\hline 4 & Efficiency & Average & High \\
\hline 5 & Power-Factor control & No (always lagging) & Yes (can lead and lag) \\
\hline 6 & Cost & Low & High \\
\hline
\end{tabular}

\subsubsection{PM motors}

PM motors are considered best because of good power density, has very good power factor and suitable control strategy could be applied so as to track load requirements. It has got no slip-rings and brush for field since air gap flux is established with magnets on the rotor circuit. However, it has practical difficulties in terms of manufacturing and assembly. This is because for such huge torque requirements of $100 \mathrm{~s}$ of $\mathrm{KNm}$, and motor manufactured in segments and assembling at site, is a difficult task. It needs huge fixtures and extremely skilled approach for safe assembly. Also with variation of air gap while assembly, may introduce huge unbalance forces on the bearings, which may reduce life of bearings and increase maintenance. Considering advantages like compact, efficient and ease of control for Mill operation, PM motors are still being considered and research is being carried out worldwide for overcoming various difficulties for implementation of these machines.

\section{Advantages of GMD:}

1) Reduced maintenance and minimized risk of downtime by reducing number of parts. Hence higher plant productivity and availability.

2) Up to $4 \%$ higher energy efficiency can be achieved with gearless drive (at nominal power and speed).

3) Higher available power at the driven component, surpassing the mechanical limits of gearboxes.

4) Smaller footprint of complete drive train.

5) Equipment provides the possibility to scale up and increase the power transmitted to the driven machine resulting in a possible increase of throughput.

6) The air gap of a GMD is rather large (15-20 mm). Therefore, the system is not sensitive to small misalignments between the stator and the rotor, and special alignment procedures are not required.

\section{Disadvantages of GMD:}

1) Because of physical size and MW power requirements (> $30 \mathrm{MW}$ ), the motor cannot be manufactured in one piece. The stator $\&$ rotor are made of many segments and hence calls for special assembly requirement.

2) Larger grinding mills have the drawback of being a bottleneck when one unit goes out of service, huge production loss is feared. Hence reliability and availability is a major concern.

\section{POWER CONVERTERS FOR MILLS [4][6]}

About 30 years ago a small number of drives were variable speed and most installed motors were fixed speed. Eighty percent of the variable speed solutions were accomplished with DC drives and the rest were based on the slip energy recovery system with a wound rotor motor or AC drives. Improvements in the power electronic components, 


\section{International Journal of Engineering Applied Sciences and Technology, 2021 \\ Vol. 6, Issue 4, ISSN No. 2455-2143, Pages 171-194 \\ Published Online August 2021 in IJEAST (http://www.ijeast.com)}

availability of efficient DSP controllers and the extensive reductions in costs and dimensions of the hardware has revolutionized the drives. Nowadays, the efficient and reliable technology of AC drives has overtaken the DC solutions which have practically disappeared from the market on new installations. This evolution from fixed speed through DC to AC variable speed brought additional benefits from the electrical, mechanical and operational point of view. Due to the high power requirement, medium voltage (MV) drives are the best solution on mill drives. MV drives require fewer cables than LV solutions and the efficiency of the complete system is higher due to less current. Basic requirements for power converter drives for GMD mills are as follows:

1) Very good efficiency $>98 \%$

2) Input Line Harmonics control to comply with IEEE-519 and output harmonic control to minimize motor heating.

3) Modular design with minimum component count to ensure reliability and easy maintenance.

4) Fine speed control capability to take care of optimization of Mill operation.

5) Very low speed operation for creeping, inching operation for start-up and maintenance.

6) High dynamic performance, regenerative braking capability, and four-quadrant operation.

GMDs require high power and very low speed about 0-10 RPM. Presently cyclo-converter is being used as an effective and acceptable drive solution. These drives use thyristors as basic switching elements. With improved and rugged power electronic switches like IGT and IGBTs, multilevel voltage source inverter technology is likely to find the right answer for compact, efficient and reliable solution.

\subsection{Cyclo-converter [6] [27]}

The cyclo-converter is a frequency changer which converts a poly-phase voltage with the frequency $f_{1}$ into a single or polyphase voltage with a lower frequency $f_{2}$. In the case of the gearless mill drives the operational output frequency is from $0.3 \mathrm{~Hz}$ up to about $10 \mathrm{~Hz}$. The cyclo-converter is classified in the group of line-commutated converters. The output current of a converter is controlled to obtain a sinusoidal shape with a given frequency, as shown on Fig 8.1.

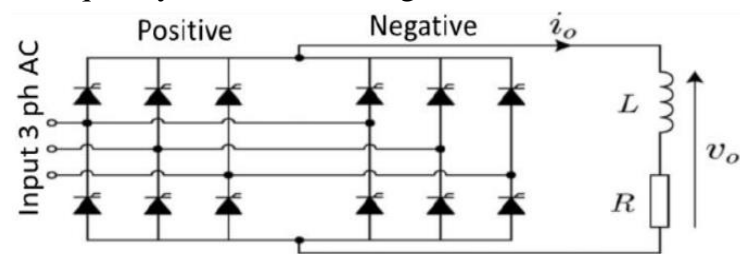

(a)

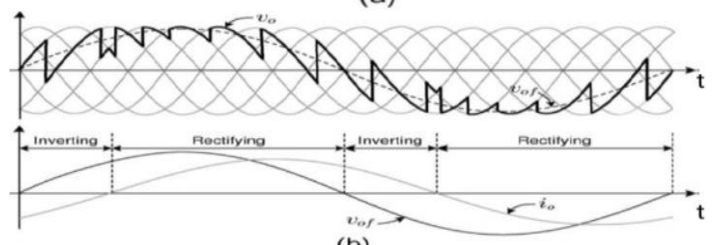

(b)
Fig. 8.1. Six-pulse Cycloconverter (a) circuit (b) output[6] The basic unit is generally a three-phase bridge where a threephase voltage is converted into a direct voltage, positive side by positive bridge and negative side by negative bridge as shown. In this way, the converter output is a positive, rectified voltage in rectifier operation, or a negative, rectified voltage in inverter operation. By means of phase-angle control this voltage can be continuously varied from zero to roughly the maximum phase-to-phase AC voltage. The reactive power of commutation required for the transfer of current between the individual legs of each bridge is obtained from the power system. A complete 3-phase cyclo-converter circuit for SM with excitation control is shown in Fig 8.2.
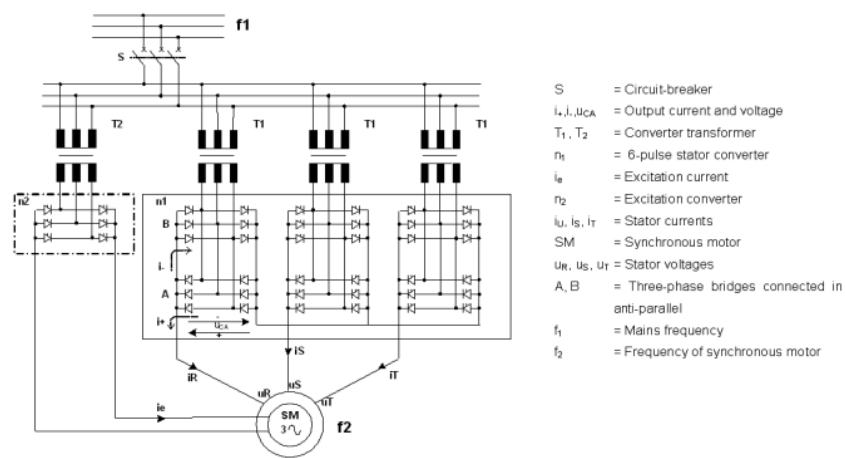

Fig 8.2. 6-pulse cyclo-converter typical circuit [4]

\section{Advantages of Cyclo-converters}

1) The drive has an inherent 4-quadrant operation allowing reversible rotation and the controlled roll back of the mill. The last one is achieved by feeding the braking energy back to the network.

2) The high efficiency of a direct drive.

3) The flexibility of selecting the optimal motor voltage

4) Compact construction.

5) Good performance at low speeds, including overloading capability required during starting.

Dis-advantages of Cyclo-converters

1) The power factor is relative low and not constant over the entire speed range. The reactive power is supplied by supply network and may affect other loads.

2) The drive generates harmonics and inter-harmonics. The total harmonic distortion depends also on the number of pulses of the cyclo-converter.

\subsubsection{Issues with Cyclo-converters \\ 1) Reliability aspects}

Cyclo-converters are built with six, 6-pulse bridges in dual converter connection using thyristors without circulating current operation. To switch off the thyristors during normal operation, the network voltage is needed for reference. When a power disturbance occurs and the cyclo-converter is operating in the inverter mode, a short circuit may happen because thyristors cannot commutate. The same effect may happen 


\section{International Journal of Engineering Applied Sciences and Technology, 2021 \\ Vol. 6, Issue 4, ISSN No. 2455-2143, Pages 171-194 \\ Published Online August 2021 in IJEAST (http://www.ijeast.com)}

under normal supply voltage but with a malfunction of the thyristor control logic. Because the motor behaves like a generator and feeds huge short circuit currents generates strong mechanical reaction forces against the poles, stator frame and foundation. Under these circumstances, pulsating torque produced can reach upto $700 \%$ of rated value. Proper mechanical design needs to ensure that the thyristors, machine and foundation can withstand such forces. The control and protection system should recognize the abnormal conditions in order to switch off the thyristors at the right time before such a short circuit is produced.

2) Power quality issues

Power quality directly affects the reliability of operation because electrical equipment may be damaged or tripped under abnormal power conditions. Harmonic currents and voltages are frequency components superimposed to the fundamental component of currents and voltages, respectively, which produces additional losses in equipment and can trip electrical protection systems. Voltage regulation and energy efficiency is affected by reactive power and also by starting of a big machinery. Operation of equipment with or without load also gives rise to transients as shown in fig 8.3.

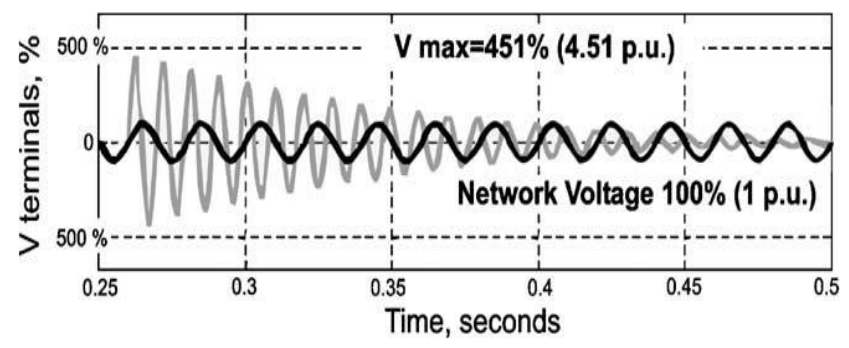

Fig 8.3. Overvoltage by off switching of a transformer under no-load condition [7]

Power quality is a major concern in the application of mill drives, mainly due to the following reasons:

(i) A failure in this equipment originates a large loss of production and

(ii) The high power of this equipment has an important impact on the operation of the power distribution system. The power factor and the current harmonics generated by the converter, has detrimental effect on other loads on the network.

\section{3) Harmonics and inter-harmonics}

Cyclo-converter has no DC-Link with energy storage components like inductors or capacitors between the network and load. That is why it injects not only harmonics but also inter-harmonics into the network. Inter-harmonics are components like lateral bands with non-integer frequencies. The frequency of theses inter-harmonics is not constant but depends on the output frequency. Cyclo-converter inject a distortion current $I_{D}$ into the network with superposition of harmonic and inter-harmonics currents components. For a 6pulse configuration the harmonic components are given by [1]:

$$
\begin{aligned}
I_{\mathrm{D}}= & \sum\left\{f_{1} \pm 6 k f_{0}\right\}+\left\{11 f_{1} \pm 6 k f_{0}\right\} \\
& +\left\{13 f_{1} \pm 6 k f_{0}\right\}+\left\{f_{2}\right\}+\left\{f_{3}\right\}+\left\{f_{4}\right\}
\end{aligned}
$$

where $\left(f_{h}+/-6 \mathrm{kf}_{0}\right)$ is a term comprising the characteristic frequency component $f_{h}$ and its lateral sidebands, $f_{1}$ is the fundamental current component of the network side $(50 \mathrm{~Hz}), \mathrm{f}_{0}$ is the output frequency of the cyclo-converter, and $\mathrm{k}$ is an integer value $\mathrm{k}=0,1,2,3, \ldots$ In addition, non-characteristics harmonics components $\mathrm{f}_{2}, \mathrm{f}_{3}, \mathrm{f}_{4}$ should also be considered, especially when parallel resonances may happen as shown in Fig 8.4. A more complex problem arises with multiple cycloconverter fed drives operating at different output frequencies. Operating frequencies when are tuned for optimization of mill performance, the harmonics also changes. this calls for comprehensive filter design over wide operating frequencies.

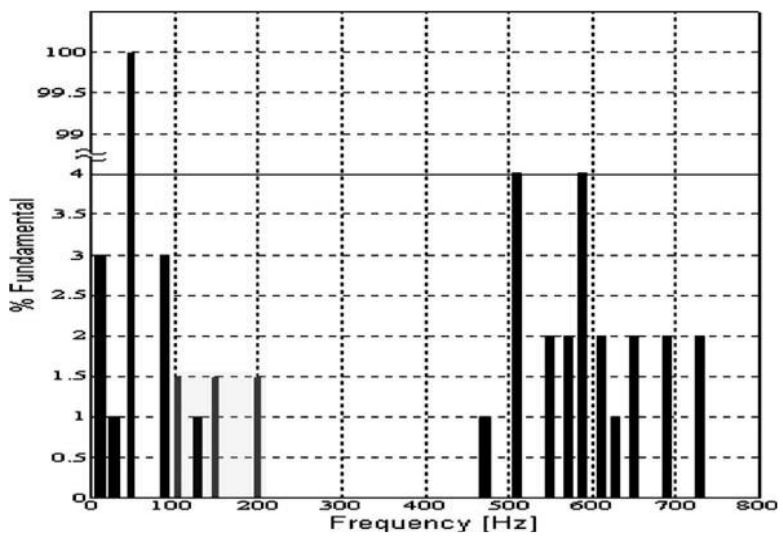

Fig. 8.4. Harmonics and inter-harmonics injected by a cyclo-converter for a given speed

\section{4) Filter design considerations}

Harmonic filters are employed to improve power factor and reduce harmonic distortion to comply with IEEE-519 guidelines. The total compensation power must be calculated using the expected active and reactive power demand of the plant under different operating conditions. Compensation power is distributed into different filter modules. To reduce harmonic voltage distortion produced by cyclo-converter, the tuning of filter branches should be carefully calculated for attenuating the characteristic harmonics and inter-harmonics. For harmonic analysis of an electrical system, the behavior of impedances at main bus bars should be considered. High impedance at parallel resonance frequencies produces increased voltage distortion for injected harmonics and interharmonics currents. Voltage distortion can cause disturbances, tripping of protections, over voltages, exceeding of harmonic limits. 


\section{International Journal of Engineering Applied Sciences and Technology, 2021 \\ Vol. 6, Issue 4, ISSN No. 2455-2143, Pages 171-194 \\ Published Online August 2021 in IJEAST (http://www.ijeast.com)}

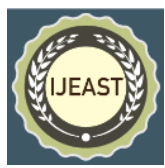

Proper design and placing of the parallel resonances at convenient frequencies is not an easy task, requiring many trade-offs between system configuration and modularity of filters with more flexibility. Variable speed operation of GMDs injects inter-harmonics with changing frequency over a broad range, increasing the chance for exciting resonances. That is why, high-pass filters with damping resistors are applied. In order to reduce the losses in the resistors, a C-Filter structure is used, especially for branches with tuning to lower frequency values. The mitigation of the lower parallel frequencies is complex and a trade-off must be designed among the reduction of voltage distortion, installation cost losses, together with maintenance and operation.

\subsection{Voltage \& Current Source Inverter (VSI\&CSI) [6,33]}

The Voltage Source Inverters (VSI) are the most common topology today and is being used with induction and synchronous motors. As shown in fig 8.5, it consists of mainly a phase shifting transformer with input filter, rectifier followed by $\mathrm{L}-\mathrm{C}$ filter for smoothening the DC voltage and an inverter which converts $\mathrm{DC}$ to $\mathrm{AC}$ with a variable frequency and voltage and again filter at the output to achieve desired THD to reduce heating and reduction of $\mathrm{dv} / \mathrm{dt}$ at motor terminals. The capacitor bank located in the DC link smoothens the voltage and supplies reactive power to the motor while uncoupling the motor from the supply network and protecting it from transients and faults.

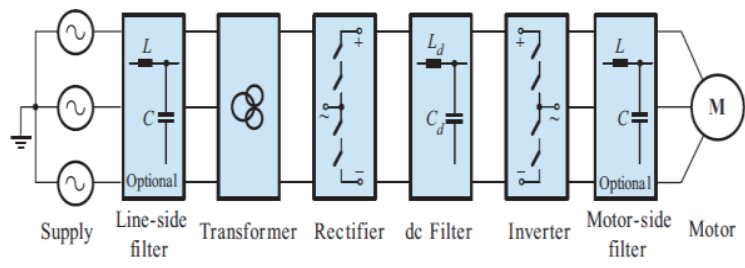

Fig 8.5. General block diagram of the VSI drive.[53]

\subsubsection{Technical Requirements and Challenges}

The technical requirements and challenges for the VSI \& CSI are generally divided into four groups: the requirements related to the power quality of line-side converters, the challenges associated with the design of motor-side converters, the constraints of the switching devices, and the drive system requirements.

\section{Line-Side Challenges}

\section{(a) Line Current Distortion.}

The rectifier normally draws distorted line current from the utility supply, and it also causes notches in voltage waveforms. This can cause numerous problems such as nuisance tripping of computer controlled industrial processes, overheating of transformers, equipment failure, computer data loss, and malfunction of communications equipment. The drive should comply with the guidelines specified by standards such as IEEE 519 for harmonic regulation $[68,69]$. (b) Input Power Factor.

High input power factor is a general requirement for all electric equipment. Most of the electric utility companies require their customers to have a power factor of 0.9 or above to avoid penalties.

(c) LC Resonance Suppression.

For the MV drives using line-side capacitors for current THD reduction or power factor compensation, the capacitors form LC resonant circuits and resonates with the line inductance of the system. The LC resonant modes may be excited by the harmonic voltages in the utility supply or harmonic currents produced by the rectifier. Since the utility supply at the medium voltage level normally has very low line resistance, the lightly damped LC resonances may cause severe oscillations or over voltages that may destroy the switching devices and other components in the rectifier circuits.

\section{Motor-Side Challenges}

(a) $d v / d t$ and Wave Reflections.

Fast switching speed of the semiconductor devices results in high $d v / d t$ at the rising and falling edges of the inverter output voltage waveform. Depending on the magnitude of the inverter dc bus voltage and speed of the switching device, the $d v / d t$ can well exceed $10,000 \mathrm{~V} / \mu \mathrm{s}$. The high $d v / d t$ in the inverter output voltage can cause premature failure of the motor winding insulation due to partial discharges. It induces rotor shaft voltages through stray capacitances between the stator and rotor producing current through shaft bearing, leading to early bearing failure.

The high $d v / d t$ may cause a voltage doubling effect at the rising and falling edges of the motor voltage waveform due to wave reflections in long cables. The reflections are caused by the mismatch between the wave impedance of the cable and the impedances at its inverter and motor ends. They can double the voltage on the motor terminals at each switching transient if the cable length exceeds a certain limit. The critical cable length for $500 \mathrm{~V} / \mu \mathrm{s}$ is in the $100-\mathrm{m}$ range, for $1000 \mathrm{~V} / \mu \mathrm{s}$ in the $50-\mathrm{m}$ range, and for $10,000 \mathrm{~V} / \mu \mathrm{s}$ in the $5-\mathrm{m}$ range is limited.

\section{(b) Common-Mode Voltage Stress.}

The switching action of the rectifier and inverter normally generates common-mode voltages. The common-mode voltages are essentially zero-sequence voltages superimposed with switching noise. If not mitigated, they will appear on the neutral of the stator winding with respect to ground, which should be zero when the motor is powered by a three-phase balanced utility supply. Furthermore, the motor line-to-ground voltage, which should be equal to the motor line-to-neutral (phase) voltage, can be substantially increased. Due to the common-mode voltages, the premature failure of the motor winding insulation system may occur shortening life expectancy of the motor.

(c) Motor De-rating.

High-power inverters may generate a large amount of current and voltage harmonics. These harmonics cause additional power losses in the motor winding and magnetic core. As a 


\section{International Journal of Engineering Applied Sciences and Technology, 2021 \\ Vol. 6, Issue 4, ISSN No. 2455-2143, Pages 171-194 \\ Published Online August 2021 in IJEAST (http://www.ijeast.com)}

consequence, the motor is de-rated and cannot operate at its full capacity.

(d) LC Resonances.

For the VSI/CSI drives with a motor-side filter capacitor, the capacitor forms an LC resonant circuit with the motor inductances. The resonant mode of the LC circuit may be excited by the harmonic voltages or currents produced by the inverter. Although the motor winding resistances may provide some damping, the problem should be addressed at the design stage of the drive.

\section{Switching Device Constraints}

(a) Device Switching Frequency.

The device switching loss accounts for a significant amount of the total power loss in the VSI/CSI drive. The switching loss minimization can lead to a reduction in the operating cost and cooling requirements. In practice, for MV drives, the device switching frequency is normally around $200 \mathrm{~Hz}$ for GTOs and $500 \mathrm{~Hz}$ for IGBTs and GCTs. The reduction of switching frequency generally causes an increase in harmonic distortion of the line and motor side waveforms of the drive.

\section{(b) Series Connection.}

Switching devices in the VSI/CSI drive are often connected in series for medium-voltage operation. Since the series connected devices and their gate drivers may not have identical static and dynamic characteristics, they may not equally share the total voltage in the blocking mode or during switching transients. A reliable voltage equalization scheme should be implemented to protect the switching devices and enhance the system reliability.

\subsubsection{Rectifiers [53]}

In an effort to comply with the stringent harmonic requirements set by guidelines such as IEEE standard 5192014 [68,69], major high-power drive use multipulse diode rectifiers like $12,18,24$ pulse type with phase shifting transformer having a number of secondary windings. The dc output of the six-pulse rectifiers is connected to a voltage source inverter.

The main feature of the multipulse rectifier lies in its ability to reduce the line current harmonic distortion. This is achieved by the phase shifting transformer, through which some of the low-order harmonic currents generated by the six-pulse rectifiers are canceled. In general, the higher the number of rectifier pulses, the lower the line current distortion is.

The multipulse rectifier has a number of other features. It normally does not require any LC filters or power factor compensators, which leads to the elimination of possible LC resonances. The use of the phase-shifting transformer provides an effective means to block common-mode voltages generated by the rectifier and inverter in medium voltage drives, which would otherwise appear on motor terminals, leading to a premature failure of winding insulation.

\section{a) 12-Pulse Diode Rectifier}

There are two identical six-pulse diode rectifiers powered by a phase-shifting transformer with two secondary windings $[56,57,65]$. The dc outputs of the six-pulse rectifiers are connected in series. It can be seen in fig 8.7 that this circuit reduces THD below $10 \%$ for $50 \%$ load and power factor better than 0.95 this is without any additional filters.

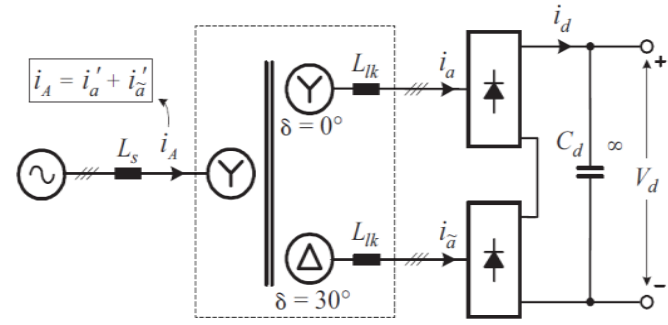

Fig 8.6. 12-pulse series-type series rectifier
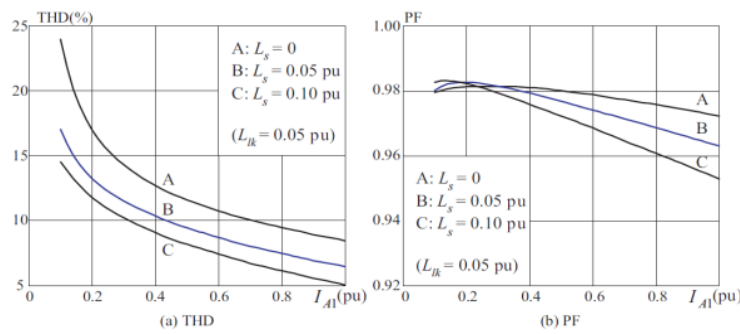

Fig 8.7. Line current THD and PF of 12-pulse series rectifier

\section{b) 18-Pulse Diode Rectifier}

The block diagram of an 18-pulse series-type diode rectifier is shown in Figure 8.8. The rectifier has three units of identical six pulse diode rectifiers fed by a phase shifting transformer. The sign " $Z$ " enclosed by a circle represents a three-phase zigzag connected winding, which provides a required phase displacement $\delta$ between the primary and secondary line-to-line voltages. The 18-pulse rectifier is able to eliminate four dominant harmonics (the $5^{\text {th }}, 7^{\text {th }}, 11^{\text {th }}$, and $13^{\text {th }}$ ). This can be achieved by employing a phase-shifting transformer with a $20^{\circ}$ phase displacement between any two adjacent secondary windings. This circuit reduces THD below $4 \%$ for $50 \%$ load and power factor better than 0.96 shown in figure 8.9.

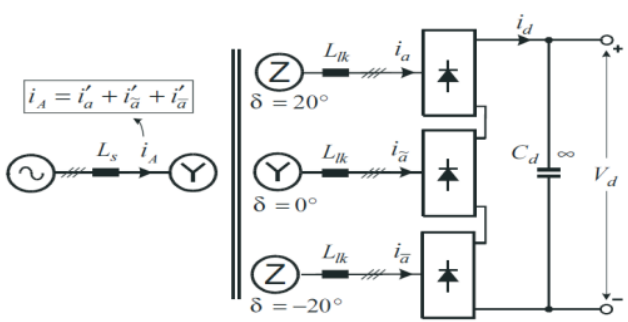

Fig 8.8. The 18-pulse series-type rectifier 


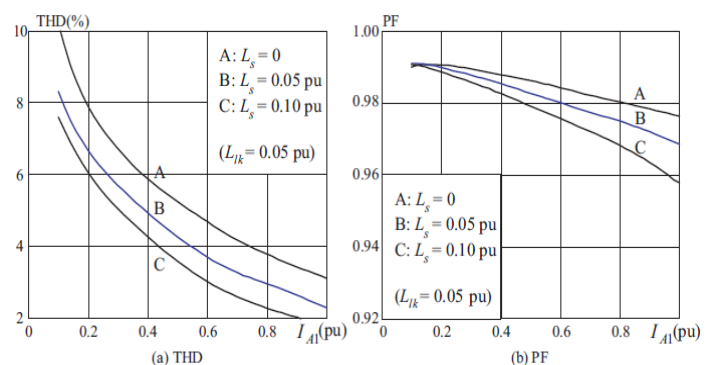

Fig 8.9. THD and PF of the 18-pulse series-type rectifier.

\section{c) 24-Pulse Diode Rectifier}

The configuration of a 24-pulse series-type diode rectifier is shown in Fig. 8.10, where a phase-shifting transformer is used to power four sets of six-pulse diode rectifiers. To eliminate six dominant current harmonics (the $5^{\text {th }}, 7^{\text {th }}, 11^{\text {th }}, 13^{\text {th }}, 17^{\text {th }}$, and $19^{\text {th }}$ ), the transformer should be arranged such that there is a $15^{\circ}$ phase displacement between the voltages of any two adjacent secondary windings. This circuit reduces THD below $2 \%$ and power factor better than 0.96 without filters as shown in Fig. 8.11.

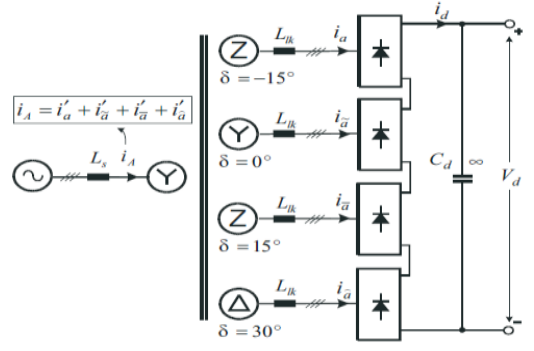

Fig 8.10. The 24-pulse series-type rectifier

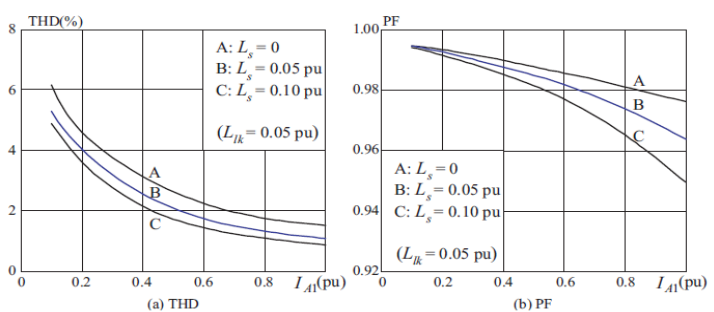

Fig 8.11. THD and PF of the 24-pulse series-type rectifier

\subsubsection{Voltage Source Inverters (VSI)}

The self-commutated inverter use High Voltage Insulated Gate Bipolar Transistor (IGBT) or Integrated Gate Commutated Thyristor (IGCT), with both two or higher level topologies.

\section{a)Two-Level Voltage Source Inverter [80,81]}

The simplest topology is the two levels voltage source inverter. This switches P (+) to N (-) voltage in the DC link as shown in fig. 8.13 creating the output phase voltage which can be varied as well as the output frequency by modifying the switching pattern. The inverter is composed of six group of active switches, $S_{1} \sim S_{6}$, with a free-wheeling diode in parallel with each switch as shown in Fig. 8.12. Depending on the dc operating voltage of the inverter, each switch group consists of two or more IGBT or GCT switching devices connected in series $[58,59]$.

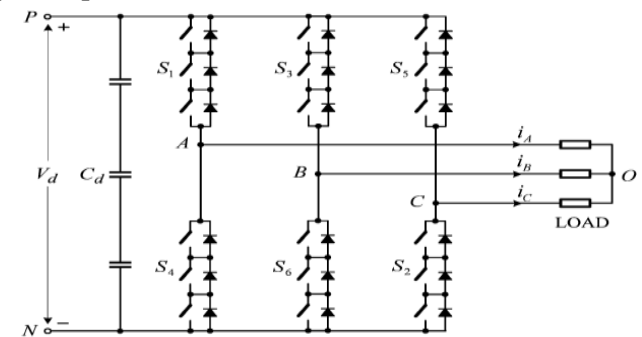

Fig 8.12. Simplified two-level inverter

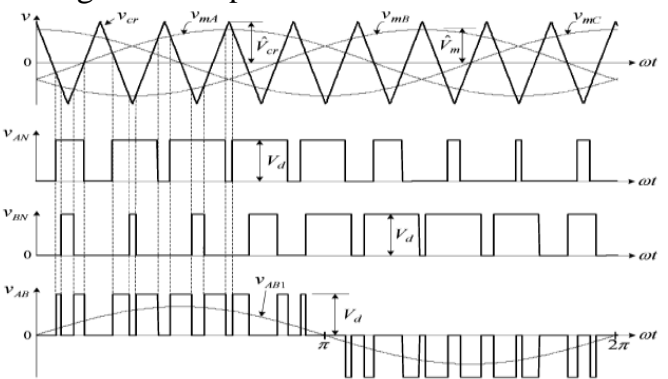

Fig 8.13. Sinusoidal pulse-width modulation (SPWM).

For output frequency and voltage control various PWM schemes are used. Most common is sinusoidal modulation where pulse width of output is varied proportional to sinusoidal reference. The switching frequency of the inverter is usually limited to a few hundred hertz for high-power medium-voltage (MV) drives because of heating problems.

\section{Advantages of two level Inverter}

1) Simple construction, less number of devices.

2) Output THD can be controlled by sinusoidal modulation, selective harmonic elimination etc.

Disadvantages of two level Inverter

1) The large $\mathrm{dv} / \mathrm{dt}$ created by the switching 2- levels of full DC voltage \& harmful to motor insulations.

2) THD in its output voltage is high and often requires a large-size LC filter installed at its output terminals.

3) Due to large DC link voltage, devices are connected in series which introduces complexity in terms of voltage sharing problems in individual devices.

\section{b) H-Bridge Inverters [58,69]}

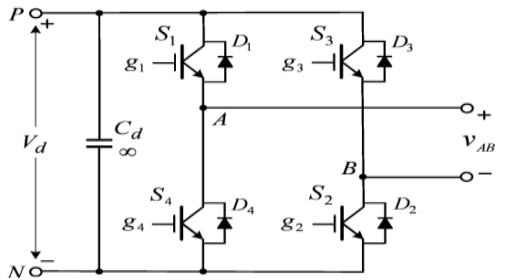




\section{International Journal of Engineering Applied Sciences and Technology, 2021 \\ Vol. 6, Issue 4, ISSN No. 2455-2143, Pages 171-194 \\ Published Online August 2021 in IJEAST (http://www.ijeast.com)}

Fig 8.14 Single-phase H-bridge inverter

H-bridge is a power cell consisting of single phase bridge Inverter structure as shown in fig. 8.14. It has Input as DC terminals and Output as AC terminals. This bridge is considered as independent module and number of them are used to construct single leg of three phase Inverter. This topology is called as Cascaded H-bridge (CHB) multilevel inverter and it is one of the popular converter topologies used in high-power medium-voltage (MV) drives [56,58,62]. It is composed of a multiple units of single-phase H-bridge power cells. The H-bridge cells are normally connected in cascade on their ac side to achieve medium-voltage operation and low harmonic distortion.

In practice, the number of power cells in a $\mathrm{CHB}$ inverter is mainly determined by its operating voltage and manufacturing cost. For instance, in the MV drives with a rated line-to-line voltage of $3300 \mathrm{~V}$, a nine-level inverter can be used, where the $\mathrm{CHB}$ inverter has a total of 12 power cells using $600 \mathrm{~V}$ class components. The use of identical power cells leads to a modular structure, which is an effective means for cost reduction.

The CHB multilevel inverter requires a number of isolated dc supplies, each of which feeds an H-bridge power cell. The dc supplies are normally obtained from multi-pulse diode rectifiers. For the seven and nine level inverters, 18 and 24 pulse diode rectifiers can be employed, respectively to achieve low line-current harmonic distortion and high input power factor.

\section{c) Cascaded H-Bridge Inverter with Equal dc Voltage}

The cascaded H-bridge multilevel inverter uses multiple units of H-bridge power cells connected in a series chain to produce high ac voltages $[56,58,62]$. A typical configuration of a fivelevel CHB inverter is shown in Fig. 8.15, where each phase leg consists of two H-bridge cells powered by two isolated dc supplies of equal voltage $E$. [71,76,82,83]

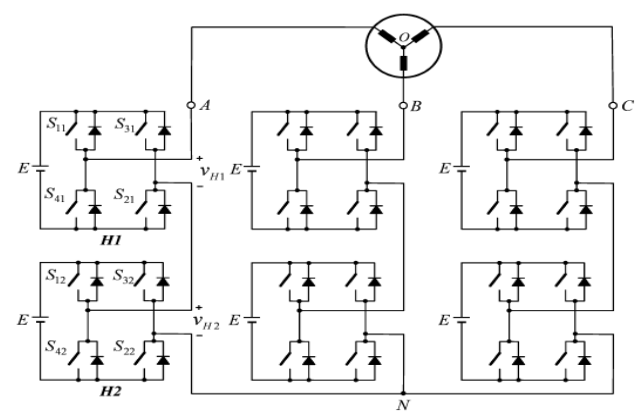

Fig 8.15. Five-level cascaded H-bridge inverter.

Table 8.16

Voltage Level and Switching State of 5-Level CHB Inverter

\begin{tabular}{|c|c|c|c|c|c|c|}
\hline \multirow{2}{*}{$\begin{array}{c}\text { Output Voltage } \\
\qquad V_{A N}\end{array}$} & \multicolumn{4}{|c|}{ Switching State } & \multirow[b]{2}{*}{$v_{H}$} & \multirow[b]{2}{*}{$v_{H 2}$} \\
\hline & $S_{11}$ & $S_{31}$ & $S_{12}$ & $S_{32}$ & & \\
\hline $2 E$ & 1 & 0 & 1 & 0 & $E$ & $E$ \\
\hline \multirow[t]{4}{*}{$E$} & 1 & 0 & 1 & 1 & E & 0 \\
\hline & 1 & 0 & 0 & 0 & E & 0 \\
\hline & 1 & 1 & 1 & 0 & 0 & E \\
\hline & 0 & 0 & 1 & 0 & 0 & E \\
\hline \multirow[t]{6}{*}{0} & 0 & 0 & 0 & 0 & 0 & 0 \\
\hline & 0 & 0 & 1 & 1 & 0 & 0 \\
\hline & 1 & 1 & 0 & 0 & 0 & 0 \\
\hline & 1 & 1 & 1 & 1 & 0 & 0 \\
\hline & 1 & 0 & 0 & 1 & E & $-E$ \\
\hline & 0 & 1 & 1 & 0 & $-E$ & E \\
\hline \multirow[t]{4}{*}{$-E$} & 0 & 1 & 1 & 1 & $-E$ & 0 \\
\hline & 0 & 1 & 0 & 0 & $-E$ & 0 \\
\hline & 1 & 1 & 0 & 1 & 0 & $-E$ \\
\hline & 0 & 0 & 0 & 1 & 0 & $-E$ \\
\hline$-2 E$ & 0 & 1 & 0 & 1 & $-E$ & $-E$ \\
\hline
\end{tabular}

The CHB inverter in Fig. 8.15 can produce a phase voltage with five voltage levels. When switches $S_{11}, S_{21}, S_{12}$, and $S_{22}$ conduct, the output voltage of the $\mathrm{H}$ bridge cells $H 1$ and $H 2$ is $v_{H 1}=v_{H 2}=E$, and the resultant inverter phase voltage is $v_{A N}=$ $v_{H 1}+v_{H 2}=2 E$, which is the voltage at the inverter terminal $A$ with respect to the inverter neutral $N$. Similarly, with $S_{31}, S_{41}$, $S_{32}$, and $S_{42}$ switched on, $v_{A N}=-2 E$. The other three voltage levels are $E, 0$, and $-E$, which correspond to various switching states summarized in Table 8.16.

It can be observed that some voltage levels can be obtained by more than one switching state. The voltage level $E$, for instance, can be produced by four sets of different (redundant) switching states. The switching state redundancy is a common phenomenon in multilevel converters \& provides a great flexibility for switching pattern design, especially for space vector modulation schemes. The number of voltage levels in a $\mathrm{CHB}$ inverter is given as:

$$
m=(2 H+1)
$$

where, $H$ is the number of $H$-bridge cells per phase leg. The voltage level $m$ is always an odd number for the CHB inverter while in other multilevel topologies such as diode-clamped inverters, it can be either an even or odd number. The CHB inverter introduced above can be extended to any number of voltage levels.

The per-phase diagram of seven and nine level inverter is depicted in Fig. 8.17, where the seven level inverter has three $\mathrm{H}$-bridge cells in cascade while the nine level has four cells in series. The total number of active switches (IGBTs) used in the $\mathrm{CHB}$ inverters can be calculated by

$$
N_{s w}=6(m-1),
$$



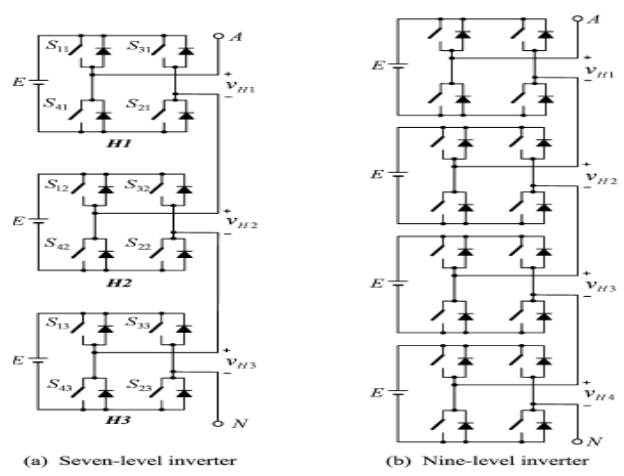

Fig 8.17. Per-phase diagram of $7 \& 9$ level CHB inverters

The dc supply voltages of the H-bridge power cells chosen above is E and same for all the cells. Alternatively, different dc voltages may be selected for the power cells. With unequal $\mathrm{dc}$ voltages, the number of voltage levels can be increased without adding number of $\mathrm{H}$-bridge cells in cascade. This allows more voltage steps in the inverter output voltage waveform for a given number of power cells.

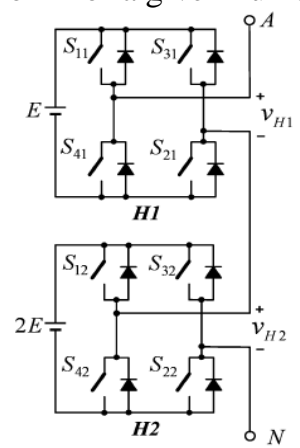

(a) Two-cell seven-level topology

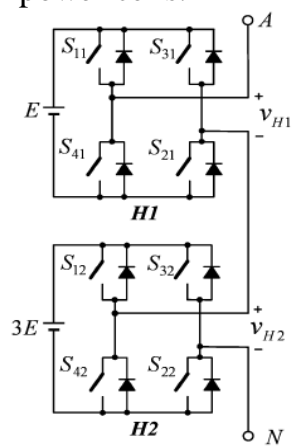

(b) Two-cell nine-level topology
Fig 8.18. CHB inverters with unequal dc voltages

Fig. 8.18 shows two inverter topologies, where the dc voltages for the $\mathrm{H}$ bridge cells are not equal. In the seven-level topology, the dc voltages for $H 1$ and $H 2$ are $E$ and $2 E$, respectively. The two-cell inverter leg is able to produce seven voltage levels: $3 E, 2 E, E, 0,-E,-2 E$, and $-3 E$. The relationship between the voltage levels and their corresponding switching states is summarized in Table 8.2.

In the nine-level topology, the dc voltage of $H 2$ is three times that of H1. All the nine voltage levels can be obtained by replacing the $H 2$ output voltage of $v H 2= \pm 2 E$ in Table 8.2 with $v H 2= \pm 3 E$ and then calculating the inverter phase voltage $v A N$.

\section{Table 8.2}

Voltage Level and Switching State of the two cell Even Level CHB Inverter with Unequal dc Voltages

\begin{tabular}{cccccrc}
\hline \multirow{2}{*}{$\begin{array}{c}\text { Output Voltage } \\
v_{A N}\end{array}$} & \multicolumn{7}{c}{ Switching State } & & \\
\cline { 2 - 5 } & $S_{11}$ & $S_{31}$ & $S_{12}$ & $S_{32}$ & $v_{H 1}$ & $v_{H 2}$ \\
\hline $3 E$ & 1 & 0 & 1 & 0 & $E$ & $2 E$ \\
$2 E$ & 1 & 1 & 1 & 0 & 0 & $2 E$ \\
$E$ & 0 & 0 & 1 & 0 & 0 & $2 E$ \\
& 1 & 0 & 1 & 1 & $E$ & 0 \\
& 1 & 0 & 0 & 0 & $E$ & 0 \\
0 & 0 & 1 & 1 & 0 & $-E$ & $2 E$ \\
& 0 & 0 & 0 & 0 & 0 & 0 \\
& 0 & 0 & 1 & 1 & 0 & 0 \\
$-E$ & 1 & 1 & 0 & 0 & 0 & 0 \\
& 1 & 1 & 1 & 1 & 0 & 0 \\
$-2 E$ & 0 & 1 & 1 & 1 & $-E$ & $-2 E$ \\
$-3 E$ & 0 & 1 & 0 & 0 & $-E$ & 0 \\
& 1 & 1 & 0 & 1 & 0 & $-2 E$ \\
& 0 & 0 & 0 & 1 & 0 & $-2 E$ \\
& 0 & 1 & 0 & 1 & $-E$ & $-2 E$ \\
\hline
\end{tabular}

There are some drawbacks associated with the CHB inverter using unequal dc voltages. The merits of the modular structure are essentially lost. In addition, switching pattern design becomes much more difficult due to the reduction in redundant switching states. Therefore, this inverter topology has limited industrial applications.

\section{Advantages of CHB multilevel inverter}

1) Modular structure. The multilevel inverter is composed of multiple units of identical $\mathrm{H}$-bridge power cells, which leads to a reduction in manufacturing cost.

2)Lower voltage THD and $d v / d t$. The inverter output voltage waveform is formed by several voltage levels with small voltage steps. Compared with a two-level inverter, the CHB multilevel inverter can produce an output voltage with much lower THD and $d v / d t$;

3)High-voltage operation without switching devices in series. The H-bridge power cells are connected in cascade to produce high ac voltages. The problems of equal voltage sharing for series-connected devices are eliminated;

\section{Disadvantages of CHB multilevel Inverter}

1) Large number of isolated dc supplies. The dc supplies for the CHB inverter are usually obtained from a multi-pulse diode rectifier employing an expensive phase shifting transformer;

2) High component count. The $\mathrm{CHB}$ inverter uses a large number of IGBT modules. A nine-level CHB inverter requires 64 IGBTs with the same number of gate drivers.

\section{d) Diode Clamped Multilevel Inverters}

The diode-clamped multilevel inverter employs clamping diodes and cascaded dc capacitors to produce ac voltage waveforms with multiple levels. The inverter can be generally configured as a three, four, or five level topology, but only the three-level inverter, often known as neutral-point clamped (NPC) inverter, has found wide application in high-power medium voltage (MV) drives.

The main features of the NPC inverter include reduced $d v / d t$ and THD in its ac output voltages in comparison to the twolevel inverter discussed earlier. More importantly, the inverter can be used in the MV drive to reach a certain voltage level without switching devices in series. For instance, the NPC 
inverter using $6000 \mathrm{~V}$ devices is suitable for the drives rated at $4160 \mathrm{~V}$.

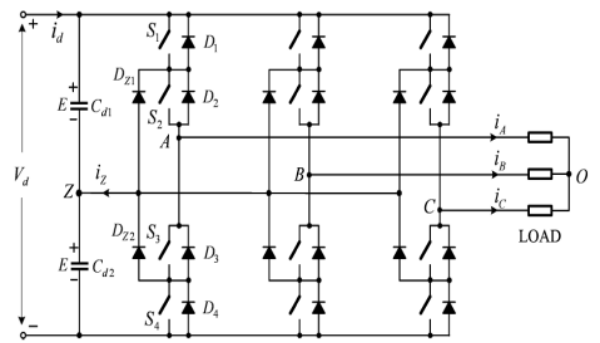

Fig 8.19. Three-level NPC inverter

Table 8.3

Definition of Switching States

\begin{tabular}{cccccc}
\hline \multirow{2}{*}{$\begin{array}{c}\text { Switching } \\
\text { State }\end{array}$} & \multicolumn{3}{c}{ Device Switching Status (Phase $A$ ) } & $\begin{array}{c}\text { Inverter Terminal } \\
\text { Voltage }\end{array}$ \\
\cline { 2 - 5 } & $S_{1}$ & $S_{2}$ & $S_{3}$ & $S_{4}$ & $v_{A Z}$ \\
\hline $\mathrm{P}$ & On & On & Off & Off & $E$ \\
$O$ & Off & On & On & Off & 0 \\
$\mathrm{~N}$ & Off & Off & On & On & $-E$
\end{tabular}

As shown in fig. 8.19 the dc bus capacitor is split into two, providing a neutral point $Z$. The diodes connected to the neutral point, $D_{Z 1}$ and $D_{Z 2}$, are the clamping diodes. When switches $S_{2}$ and $S_{3}$ are turned on, the inverter output terminal $A$ is connected to the neutral point through one of the clamping diodes. The voltage across each of the dc capacitors is $E$, which is normally equal to half of the total dc voltage $V_{d}$. With a finite value for $C_{d 1}$ and $C_{d 2}$, the capacitors can be charged or discharged by neutral current $i_{Z}$, causing neutral-point voltage deviation.

Switching States:

The operating status of the switches in the NPC inverter can be represented by switching states shown in Table 8.3. Switching state ' $\mathrm{P}$ ' denotes that the upper two switches in leg $A$ are on and the inverter terminal voltage $v_{A Z}$, which is the voltage at terminal $A$ with respect to the neutral point $Z$, is $+E$, whereas ' $\mathrm{N}$ ' indicates that the lower two switches conduct, leading to $v_{A Z}=-E$.

Switching state 'O' signifies that the inner two switches $S_{2}$ and $S_{3}$ are ON and $v_{A Z}$ is clamped to zero through the clamping diodes. Depending on the direction of load current $i_{A}$, one of the two clamping diodes is turned on. For instance, a positive load current $\left(i_{A}>0\right)$ forces $D_{Z 1}$ to turn on, and the terminal $A$ is connected to the neutral point $Z$ through the conduction of $D_{Z 1}$ and $S_{2}$. It can be observed from Table 8.3 that switches $S_{1}$ and $S_{3}$ operate in a complementary manner.

Fig.8.20 and 8.21 shows how the line-to-line voltage waveform is obtained. The inverter terminal voltages $v_{A Z}, v_{B Z}$, and $v_{C Z}$ are three-phase balanced with a phase shift of 120 degree between each other. The line-to-line voltage $v_{A B}$ can be found from $v_{A B}=v_{A Z}-v_{B Z}$, which contains five voltage levels $(+2 E,+E, 0,-E$, and $-2 E)$.

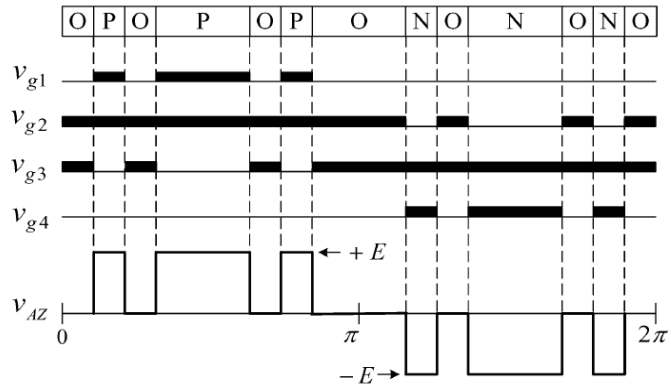

Fig 8.20. Switching states, gate signals and waveform of NPC Inverter

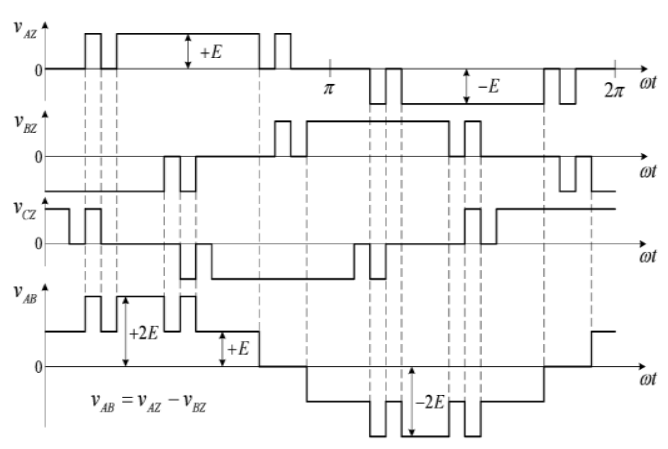

Fig 8.21. Inverter terminal and line-to-line voltage terminal voltage $v_{A Z}$ waveforms.

Advantages of NPC Inverter

1) No dynamic voltage sharing problem in devices. Each of the switches in the NPC inverter withstands only half of the total dc voltage during commutation.

2) Static voltage equalization without using additional components. The static voltage equalization can be achieved when the leakage current of the top and bottom switches in an inverter leg is selected to be lower than that of the inner switches.

3) Low THD and $d v / d t$. The line-to-line voltages is composed of five voltage levels, which leads to lower THD and $d v / d t$ in comparison to the two-level inverter operating at the same voltage rating and device switching frequency.

Disadvantages of NPC Inverter

1) Needs additional clamping diodes

2) Complicated PWM switching pattern is required

3) Possibility of deviation of neutral point voltage.

\section{Neutral-Point Voltage Control in NPC Inverter}

The neutral-point voltage $v_{Z}$ varies with the operating condition of the NPC inverter. If the neutral-point voltage deviates too far, an uneven voltage distribution takes place, which may lead to premature failure of the switching devices and cause an increase in the THD of the output voltage.

Causes of Neutral-Point Voltage Deviation 


\section{International Journal of Engineering Applied Sciences and Technology, 2021 \\ Vol. 6, Issue 4, ISSN No. 2455-2143, Pages 171-194 \\ Published Online August 2021 in IJEAST (http://www.ijeast.com)}

In addition to the influence of switching voltage, the neutralpoint voltage may also be affected by a number of following factors,

1) Unbalanced dc capacitors due to tolerances.

2) Inconsistency in switching device characteristics.

3) Unbalanced three-phase operation.

To minimize the neutral-point voltage shift, a feedback control scheme can be implemented, where the neutral-point voltage is detected and then controlled.

\section{e) Four and Five Level Diode-Clamped Inverter}

To increase the inverter voltage rating and improve its waveform quality, high-level diode-clamped inverters are employed [56,58]. The schematic is as shown in fig. 8.21.

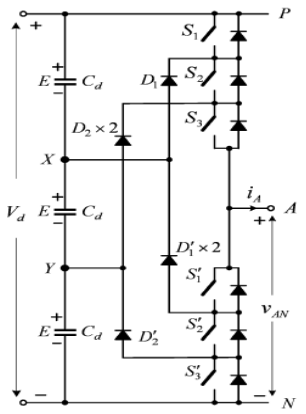

(a) Four-level $(m=4)$

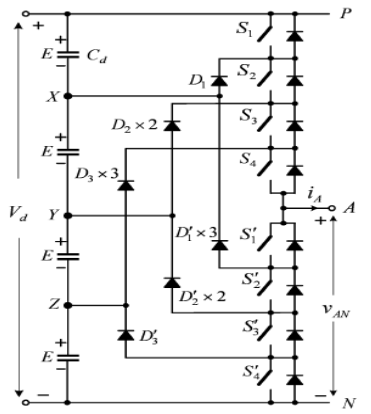

(b) Five-level $(m=5)$
Fig 8.21. Per-phase diagram of $4 \&$ 5-level diode clamped inverters.

Table 8.4

Switch Status and Inverter Terminal Voltage $v_{A N}$

\begin{tabular}{|c|c|c|c|c|c|c|c|c|}
\hline \multicolumn{9}{|c|}{ Switch Status } \\
\hline \multicolumn{8}{|c|}{ Four-Level Inverter } & \\
\hline$S_{1}$ & & $S_{2}$ & $S_{3}$ & $S_{1}^{\prime}$ & & $S_{2}^{\prime}$ & $S_{3}^{\prime}$ & $v_{A N}$ \\
\hline 1 & & 1 & 1 & 0 & & 0 & 0 & $3 E$ \\
\hline 0 & & 1 & 1 & 1 & & 0 & 0 & $2 E$ \\
\hline 0 & & 0 & 1 & 1 & & 1 & 0 & $E$ \\
\hline 0 & & 0 & 0 & 1 & & 1 & 1 & 0 \\
\hline \multicolumn{8}{|c|}{ Five-Level Inverter } & \\
\hline$S_{1}$ & $S_{2}$ & $S_{3}$ & $S_{4}$ & $S_{1}^{\prime}$ & $S_{2}^{\prime}$ & $S_{3}^{\prime}$ & $S_{4}^{\prime}$ & $v_{A N}$ \\
\hline 1 & 1 & 1 & 1 & 0 & 0 & 0 & 0 & $4 E$ \\
\hline 0 & 1 & 1 & 1 & 1 & 0 & 0 & 0 & $3 E$ \\
\hline 0 & 0 & 1 & 1 & 1 & 1 & 0 & 0 & $2 E$ \\
\hline 0 & 0 & 0 & 1 & 1 & 1 & 1 & 0 & $E$ \\
\hline 0 & 0 & 0 & 0 & 1 & 1 & 1 & 1 & 0 \\
\hline
\end{tabular}

In the four level inverter, three switches conduct at any time instant and switch pairs $\left(S_{1}, S_{1}^{\prime}\right),\left(S_{2}, S_{2}^{\prime}\right)$, and $\left(S_{3}, S_{3}^{\prime}\right)$ operate in a complementary manner.

The clamping diodes may withstand different reverse blocking voltages. For instance, when the inverter operates with $S_{1}=S_{2}$ $=S_{3}=$ " 1 ", the anode of the clamping diodes $D_{1}$ and $D_{2}$ in Fig. 8.21(a) is connected to the positive dc bus. The voltage applied to $D_{1}$ and $D_{2}$ is then $E$ and $2 E$ respectively. In practice, the voltage rating for all the clamping diodes is normally selected to be the same as the active switches. As a result, two diodes should be in series for $D_{2}$ (shown $D_{2} \times 2$ ).
Table 8.5

Component Count of Diode-Clamped Multilevel Inverters

\begin{tabular}{cccc}
\hline Voltage Level & Active Switches & Clamping Diodes $^{a}$ & dc Capacitors \\
\hline$m$ & $6(m-1)$ & $3(m-1)(m-2)$ & $(m-1)$ \\
3 & 12 & 6 & 2 \\
4 & 18 & 18 & 3 \\
5 & 24 & 36 & 4 \\
6 & 30 & 60 & 5 \\
\hline
\end{tabular}

Table 8.5 lists the component count for the multilevel diode clamped inverters. Assuming that all the active switches and clamping diodes have the same voltage rating, the rated inverter output voltage is proportional to the number of active switches. This suggests that if the number of the switches is doubled, the maximum inverter output voltage increases twofold, and so does its output power. However, the number of clamping diodes increases dramatically with the voltage level. For example, the three-level inverter requires only six clamping diodes while the five-level inverter needs 36 clamping diodes. This is, in fact, one of the main reasons why the four and five level diode clamp inverters are not preferred in industrial applications.

\section{f) NPC / H-Bridge Inverter}

The NPC/H-bridge inverter is developed from the three-level NPC inverter topology and shown in fig. 8.22. This inverter has some unique features that have promoted its application in the MV drive applications.

The output voltage and power of a three-level NPC inverter can be doubled by using 24 active switches, every two of which are connected in series. The NPC/H-bridge inverter also uses 24 active switches to achieve the same voltage and power ratings as the 24-switch NPC inverter. Each of the inverter phases is composed of two NPC legs in an H-bridge form. The $\mathrm{NPC} / \mathrm{H}$-bridge inverter has some advantages over the threelevel NPC inverter. The distinct advantage is the inverter phase voltages, $v_{A N}, v_{B N}$ and $v_{C N}$, contain five voltage levels instead of three levels for the NPC inverter, leading to a lower $d v / d t$ and THD.

The inverter does not have any switching devices in series, which eliminates the device dynamic and static voltage sharing problems. However, the inverter requires three isolated dc supplies, which increases the complexity and cost of the dc supply system. 


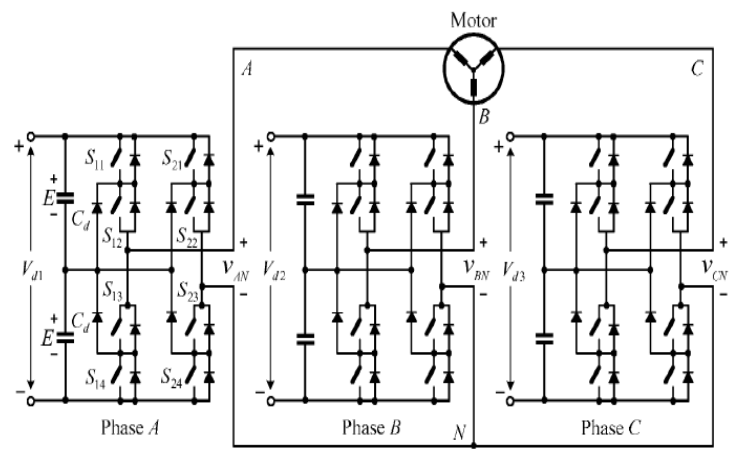

Fig 8.22. Five-level NPC/H-bridge inverter
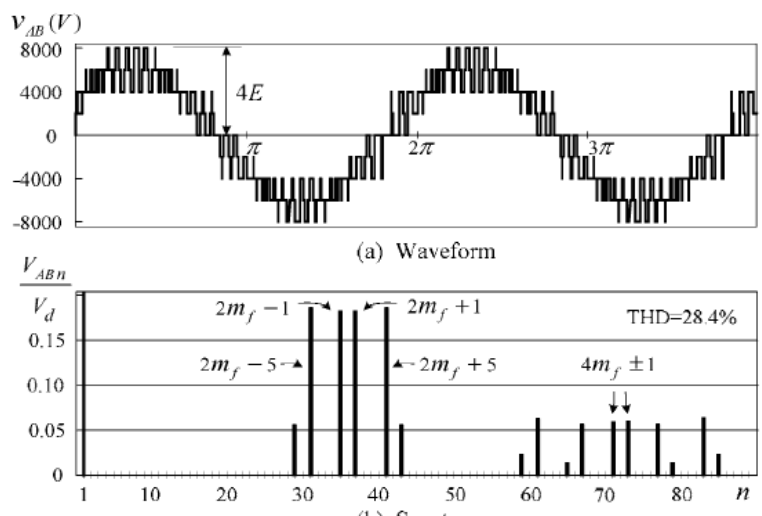

(b) Spectrum

Fig 8.23 Spectrum of the inverter line-to-line voltage

Waveforms and Harmonics of $\mathrm{NPC} / \mathrm{H}$-bridge Inverter:

The waveform for the inverter line-to-line voltage $v_{A B}$ is illustrated in Fig.8.23. It contains nine voltage levels. The triplen harmonics in $v_{A N}$ do not appear in $v_{A B}$ due to the threephase balanced system, resulting in a reduction of THD from $33.1 \%$ to 28.4 .

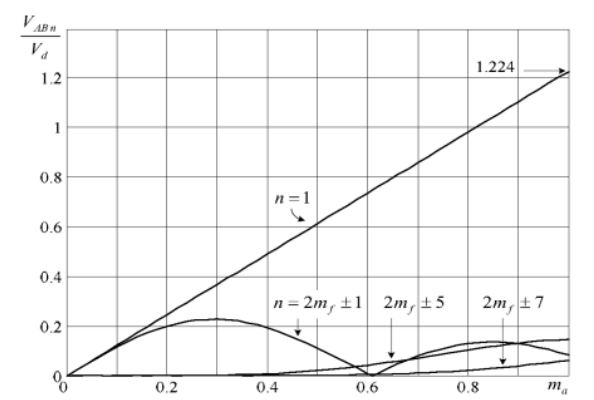

Fig 8.24. Harmonic of the 5-level NPC/H-bridge inverter $\left(m_{f}=18\right) .\left(f_{m}=50 \mathrm{~Hz}, f_{s w}, \operatorname{dev}=450 \mathrm{~Hz}, m_{f}=18\right.$, and $\left.m_{a}=0.9\right)$.

g) Multilevel Flying-Capacitor Inverters [57,73,74,84]

Fig. 8.25 shows a typical configuration of a five-level flyingcapacitor inverter $[80,81,90]$. It is evolved from the two-level inverter by adding dc capacitors to the cascaded switches. There are four complementary switch pairs in each of the inverter legs. For example, the switch pairs in leg $A$ are
$\left(S_{1}, S_{1}^{\prime}\right),\left(S_{2}, S_{2}^{\prime}\right),\left(S_{3}, S_{3}^{\prime}\right)$, and $\left(S_{4}, S_{4}^{\prime}\right)$. Therefore, only four independent gate signals are required for each inverter phase. The flying-capacitor inverter in Fig. 8.25 can produce an inverter phase voltage with five voltage levels. When switches $S_{1}, S_{2}, S_{3}$, and $S_{4}$ conduct, the inverter phase voltage $v_{A N}$ is $4 E$, which is the voltage at the inverter terminal $A$ with respect to the negative dc bus $N$. Similarly, with $S_{1}, S_{2}$, and $S_{3}$ switched on, $v_{A N}=3 E$. Table 8.6 lists all the voltage levels and switching states.

Flying-capacitor inverter topology is derived from the twolevel inverter hence it carries the same features as the twolevel inverter such as modular structure for the switching devices. It is also a multilevel inverter, producing the voltage waveforms with reduced $d v / d t$ and THD. However, the flyingcapacitor inverter has following limitations:

1) The inverter requires several banks of bulky dc capacitors, each needs a separate pre-charge circuit.

2) The dc capacitor voltages in the inverter normally vary with the inverter operating conditions. To avoid the problems caused by the dc voltage deviation, the voltages on the dc flying capacitors should be tightly controlled, which increases the complexity of the control scheme. Due to the above-mentioned drawbacks, the use of the flying-capacitor inverter in the drive system is limited.

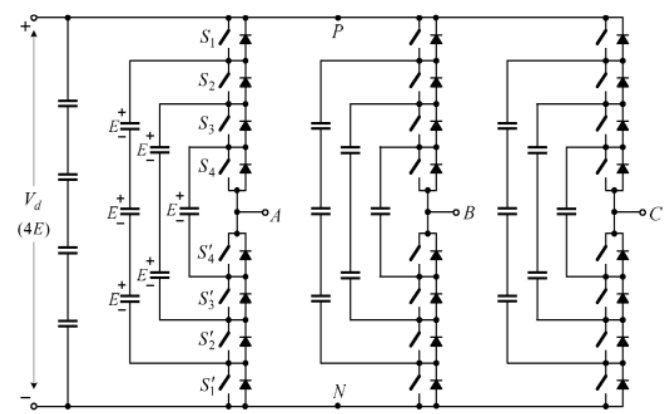

Fig 8.25. Five-level flying-capacitor inverter

Table 8.6

Switching States for 5 level Inverter

\begin{tabular}{ccccc}
\hline \multirow{2}{*}{$\begin{array}{c}\text { Inverter Phase } \\
\text { Voltage } V_{A N}\end{array}$} & \multicolumn{4}{c}{ Switching State } \\
\cline { 2 - 5 } & $S_{1}$ & $S_{2}$ & $S_{3}$ & $S_{4}$ \\
\hline $4 E$ & 1 & 1 & 1 & 1 \\
$3 E$ & 1 & 1 & 1 & 0 \\
& 0 & 1 & 1 & 1 \\
& 1 & 0 & 1 & 1 \\
$2 E$ & 1 & 1 & 0 & 1 \\
& 1 & 1 & 0 & 0 \\
& 0 & 0 & 1 & 1 \\
& 1 & 0 & 0 & 1 \\
& 0 & 1 & 1 & 0 \\
$1 E$ & 1 & 0 & 1 & 0 \\
& 0 & 1 & 0 & 1 \\
& 1 & 0 & 0 & 0 \\
0 & 0 & 1 & 0 & 0 \\
& 0 & 0 & 1 & 0 \\
& 0 & 0 & 0 & 1 \\
\hline
\end{tabular}



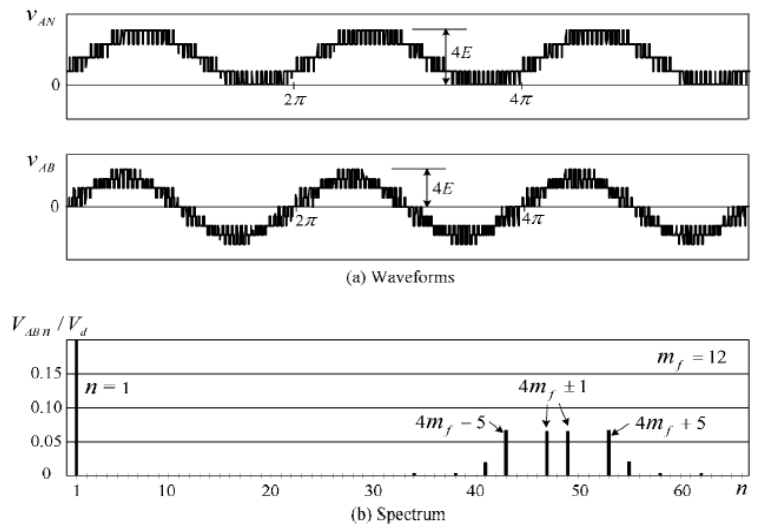

Fig 8.26. Spectrum of the five-level flying-capacitor inverter.

\subsubsection{Current Source Inverter (CSI) [6]}

CSI is similar to VSI but here current regulating choke is used in DC link instead of filter capacitors in VSI. It utilizes active switching devices on the motor side, and thus can adopt suitable PWM schemes together with advanced control strategies to improve motor dynamic performance and reduce torque ripples. Motor PF is controllable with these drives. At the line side, LCI and CSI drives have inherent regenerating capability. In contrast, a large percentage of the industrial VSI drives employ single or multi-pulse diode rectifier at the line side that prevents power to be regenerated back to the line.

CSI or VSI drives with an active front end are also capable of line PF correction. For high-power medium-voltage applications, traditional two-level VSI supplies the motor with chopped voltage waveforms and thus generates high $\mathrm{dv} / \mathrm{dt}$ at the motor terminals. Multi-level VSIs are therefore used to reduce the voltage steps and stress in the motor. CSIs, on the other hand, provide the motor load with sinusoidal output voltage and current waveforms with low harmonics because of the filter capacitor at the output. Devices can be connected in series to achieve higher voltage rating, making the structure relatively simple and robust for high voltage and power ratings.

\subsubsection{Load Commutated Inverter (LCI) [51]}

LCI drives employ SCR thyristors as switching devices. The thyristor does not have self-turn-off capability but can be naturally commutated by the load voltage with a leading PF. The LCI features low manufacturing cost and high efficiency due to the use of low-cost SCR devices and the lack of pulsewidth modulated (PWM) operation. It is a popular solution for very large drives where the initial investment and operating efficiency are important. However, the LCI itself is not a grid and motor friendly topology. It normally generates highamplitude, low-frequency current harmonics, and the grid-side PF is not controllable. Active filters or compensators of high power ratings are employed for the LCI to improve the grid side performance.
Other concerns include the difficulty of device commutation at low speed due to the low motor back EMF to commutate the inverter. A method named dc-link pulsing is commonly used to assist device commutation through intentionally created zero-current intervals. A side effect of the method is increased torque pulsation. Often these pulsations are not acceptable and a separate inching device is needed. The dynamic performance of the LCI drive is the poorest among all three due to its naturally commutated operation.

\subsubsection{Comparison of Multilevel Topologies}

The two-level inverter has the lowest cost and weight in comparison with the other topologies. But this inverter has a very high THD. Also it has high dv/dt because of level switching between positive and negative DC link voltage. It needs series connection of devices because switching devices are available with certain voltage ratings.

The cost and the weight of the 5-level multilevel inverters seem better than the 9-level multilevel inverters. By increasing the number of levels, the cost and weight of the multilevel inverter will be increased. The advantage that the 9-level multilevel inverters have over the 5-level multilevel inverters is their THD without filters. Using the 5-level inverter and a filter is a better design in terms of component count, power loss and reliability. The flying capacitor clamped inverter has the lowest power losses between all of the other, since there is no diode in this topology. Because of bulky capacitors it is heavier than the other topologies. It is not practical to use this heavy inverter in applications that are going to be used has restriction on space.

The cascaded H-bridge has the lowest weight and cost between the multilevel inverters, but its power losses are marginally higher than all other topologies because of more number of devices conducting at a time. But this topology scores over all because of modular power cells built with low voltage switching devices. Modular structure gives easy maintenance possibility hence low downtime. This topology is most suited for high power applications like GMD mills.

The diode clamped multilevel inverter power losses are lower than cascaded H-bridge. Diode clamped inverter topology have low THD, cost and power losses between other types of inverters. Only problem is increased number of components as number of levels go up.

\section{DRIVE COMPARISON FOR SAG MILLS [2].}

In the Table 9.1, the main criteria for selecting drive systems are given. This comparison is rather general. For specific project process requirements, equipment cost, system efficiency and the related energy savings as well as maintenance aspects and the related costs need to be evaluated in detail.

Table 9.1

Comparison of Drive systems for Mills 
International Journal of Engineering Applied Sciences and Technology, 2021

Vol. 6, Issue 4, ISSN No. 2455-2143, Pages 171-194

Published Online August 2021 in IJEAST (http://www.ijeast.com)

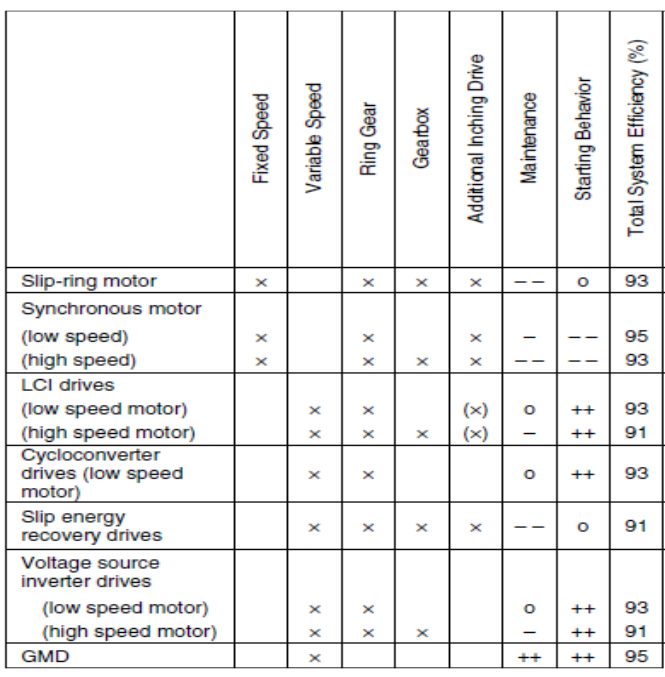

\section{ENERGY AND COST SAVINGS [2]}

Process optimization can lead to a much more efficient use of grinding power and thus to significant energy savings. Furthermore, significant energy savings can be achieved with drive systems that have high efficiency.

\subsection{Efficiency Comparison}

The evaluation of the overall system efficiency is an important decision factor during the selection of the most appropriate drive system when considering the life cycle costs. Table 10.1 shows the typical efficiency figures for a 16MW ball mill with different drive configurations. It compares dual pinion variable speed ring-geared alternatives and gearless mill drive (GMD) solution. The efficiency of the ring-gear and the gear reducer are affected by other factors, e.g. alignment, and can be significantly lower than the assumed values used for this comparison. Motor and transformer efficiencies can be improved by modifying their design and can slightly vary depending on the application and site specific conditions.

The main observation is that, the lower are the amounts of components present on the system, the higher is the overall efficiency. Variable speed grinding mill drives equipped with high speed squirrel cage induction motors, require a gear reducer and a ring-gear. If a two stage gear reducer is used, its efficiency further drops to about $97 \%$. On the other hand, the variable speed alternative using low speed synchronous motor eliminates the gear reducer, improving the overall efficiency. The Gearless Mill Drive (GMD), by removing ring gear completely is able to provide unmatched efficiency.

Table 10.1

Various components and efficiencies in mill

\begin{tabular}{|l|r|r|c|}
\hline \multicolumn{1}{|c|}{} & VSD High speed & VSD Low speed & \multicolumn{1}{c|}{ VSD GMD } \\
\hline Transformer & $99.1 \%$ & $99.1 \%$ & $99.1 \%$ \\
\hline Converter & $98.6 \%$ & $98.6 \%$ & $99.2 \%$ \\
\hline Motor & $97.2 \%$ & $97.2 \%$ & $96.8 \%$ \\
\hline Gear reducer & $98.5 \%$ & n/a & n/a \\
\hline Ring-gear & $98.0 \%$ & $98.0 \%$ & n/a \\
\hline Overall efficiency & $\mathbf{9 1 . 7 \%}$ & $\mathbf{9 3 . 1} \%$ & $\mathbf{9 5 . 2} \%$ \\
\hline
\end{tabular}

\subsection{Cost Comparison}

Several factors and cost considerations must be taken into account in the drive system evaluation. A proper evaluation and the right selection of the drive system impacts the total cost of ownership (TCO) of the mill.

The TCO analysis must include direct and indirect costs. As an example of indirect costs can be cited the loss of production related to the non-availability of the system. The GMD, by having fewer components, has the highest availability. It is followed by the low speed VSD solution and by the high speed VSD.

Also as direct costs, the efficiency and the use (including disposal costs) of lubricants on the ring-geared mills shall be considered. Plant layout is a factor for evaluation when comparing geared and gearless drives. Obviously, the footprint for gearless, single pinion and dual pinion drives is different. Single pinion drives require the smallest amount of space, but only marginally less than gearless rives. Dual pinion drives have the maximum space requirement.

The capital expenditure for gearless mill drives is typically higher than for other drive systems. However, energy savings due to higher efficiency and reduced maintenance costs usually leads to smaller lifecycle cost compared with other drive system solutions. The lowest capital expenditure is given by the high speed (VSD) solution, where the electrical equipment cost less and the mechanical part more, as a result of the inclusion of the ring-gear and gear reducer.

\subsection{Maintenance and Reduced Shut Downs}

Beside the cost savings related to energy savings additional cost savings can be achieved with reduced maintenance. GMD systems show excellent low speed characteristics without the need for any speed encoder. Cycloconverters are ideally suited for low speed applications and deliver precise and strong torque control during start up and during cascading of the material. The drive control has modes for inching and creeping. This allows fast, easy and accurate positioning of the mill and thus reduces the maintenance time needed for changing liners.

Service and maintenance for a drive system is mainly needed because there are parts that have wear such as gearboxes, bearings and carbon brushes or may get dirty or clogged such as heat exchanger tubes or air filters. These components need to be checked and replaced before the functionality cannot be guaranteed anymore, the behavior is degraded too much or the replacement would require an unplanned shutdown. It is clear that the maintenance work increases with the number of 


\section{International Journal of Engineering Applied Sciences and Technology, 2021 \\ Vol. 6, Issue 4, ISSN No. 2455-2143, Pages 171-194 \\ Published Online August 2021 in IJEAST (http://www.ijeast.com)}

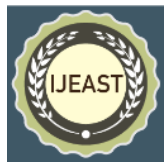

wearing components. In case of component failures, spare parts are needed on site to reduce downtime of the plant. However, proper design, operation of the equipment within safe limits and the use of supervision systems eliminate the risk of severe failures as far as possible.

Often routine maintenance of drive systems can be done during normal planned mill outages. However, the maintenance work that needs to be done for bearings, ring gears, gearboxes and other wearing parts leads to higher maintenance costs, tends to increase shutdown times and thus reduces system availability. GMD systems have only very few wearing parts, i.e. the brushes and the greaseless motor dust sealing, and therefore need relative little service and maintenance. This ultimately results in very high availability of GMD systems and lower maintenance costs compared with other drive systems.

\section{CONCLUSIONS}

Mining processes are demanding advanced technologies that improve overall efficiency, reliability and also offer important benefits to the whole chain. Grinding has now been driven by large diameter mills for increased throughput for cost competitive processing of ores. Mills have been designed upto 42 feet diameters and power about $38 \mathrm{MW}$. At such power levels the geared mills like single or double pinion has got limitations and only solution is Gearless mills (GMD).

The technology for GMD calls for low speed (0-10 RPM) ring motor wrapped around mill cylinder and manufactured in multiple segments for ease of assembly at site. The motor options are Induction motor, synchronous motor and PM motor. Presently synchronous motors are being used because it can be operated with unity or leading power factor, reduced motor current and hence reduced loss. It also offers $>140 \%$ starting torque without drawing multiple times starting current unlike induction motors.

Induction motors have operating power factor always lagging demanding more current compared to synchronous motors but it has simple and rugged construction and can help in avoiding issues related to failures in case of abnormal condition like unbalance due to winding failures etc.

PM motors are most promising because of its very high power density and ease of operation. It also can be operated at unity power factor reducing current like synchronous machine. It has issues like manufacturing in segments and assembly difficulties because of strong magnetic forces, and large unbalance forces in case of uneven air gap which may result into failure of bearings.

Presently for driving GMD, cyclo-converters are used because of compact, direct drive without intermediate converter stage, having regenerating capability. But it has disadvantage of generating harmonics and inter-harmonics in supply network. Moreover GMD needs variable speed operation for process optimization which is little tricky in case of cyclo-converter as it can not generate very fine frequency steps. Also no. of filters needs to be installed at line side and also motor side to take care of weak power supply network and heating in the motor.

With development of IGBT and IGCT devices, voltage source and current source Inverter offer good alternative to cycloconverters. The multilevel and H-bridge Inverters with $12,18,24$ pulse rectifiers with phase shifting transformer at input presents good input THD performance with very minimum filters. Also Inverter stage is built with IGBT with modular construction for better maintenance, low downtime and low dv/dt at the motor terminals. This configuration can be built with both VSI and CSI as per design requirements. Comparison with cyclo-converter shows that modern VSI/CSI Inverter are promising alternative to cyclo-converters. With use of various function in GMD like stop sequences to protect the mechanical system from dangerous torque kicks and reduce the wearing of mechanical elements, operation and maintenance requirement like inching can be implemented with these drives easily. Variable speed operation which offers important benefits in terms of process flexibility and process continuity to take care of changeful nature of feed material in SAG, is possible with VSI/CSI drive with very precision speed control without compromising THD limits. It can be concluded that the modern VSI/CSI drives shows a great potential for GMD application.

\section{Acknowledgements:}

The authors wish to thank Dr. R Anbarasu, GE Power Conversion, for his valuable suggestions.

\section{REFERENCES}

[1] Pontt J, Rodriguez J, Valderrama W, Sepúlveda G, Chavez P, Cuitino P, Gonzalez P, Alzamora G, "Current Issues on High-Power Cycloconverter- Fed Gearless Motor Drives for Grinding Mills", July 2003.

[2] Ahrens M, Gonser J, "Technical and Commercial Benefits of Gearless Mill Drives for Grinding Applications", SME Annual Meeting Feb. 25-Feb. 28, 2007,

[3] Rodríguez Jose R, Pontt J, Patricio Newman, Rodrigo Musalem, Miranda Hernan, Moran Luis, and Gerardo Alzamora, "Technical Evaluation and Practical Experience of High-Power Grinding Mill Drives In Mining Applications", IEEE Transactions on Industry Applications, Vol. 41, No. 3, May/June 2005.

[4] Tatiana Ravani Von Ow, Leandro Bomvisinho, "Use of the Latest Technology to Overcome the Demands of Mill Operation."

[5] Seggewiss George, Dai Jingya , Peng Mark Fanslow, "Evaluation of Synchronous Motors on Grinding Mills." 


\section{International Journal of Engineering Applied Sciences and Technology, 2021 \\ Vol. 6, Issue 4, ISSN No. 2455-2143, Pages 171-194 \\ Published Online August 2021 in IJEAST (http://www.ijeast.com)}

[6] Wu Bin, Pontt Jorge, Rodríguez Jose, Bernet Steffen, and Kouro Samir, "Current-Source Converter and Cycloconverter Topologies for Industrial Medium-Voltage Drives".

[7] Pontt J, Rodri'Guez B, Valderrama W, Sepu Lveda G, Alzamora G, Minera Chile C "Resonance Effects, Power Quality and Reliability Issues of High-Power Converters-Fed Drives Employed In Modern SAG Circuits", 29 April 2004.

[8] Green Jack H, and Stroker John J, "Ball Mill Drive Motor Choices", IEEE IPCA Cement Industry Technical Conference, May 2000.

[9] Mynhardt Coenie "Gearless Mill Drive Overview" Engineering Manager-Winders, $A B B$

[10] Kalra R, Jiangang J, DrucI, Raucher M, "Updates on Geared Vs Gearless Drive Solution for Grinding Mills",SME Annual Meeting, Feb24-27 2013.

[11] Korn A. J, Winkelnkemper M, Steimer P And Kolary J. W. "Direct Modular Multi-Level Converter for Gearless Low-Speed Drives"

[12] Andersen, Bogh Søren, "Design and Optimization of Gearless Drives Using Multi-Physics Approach", 2012.

[13] Doll A.G. and Tischler K, Alex G. "The Engineering and Process Effects of Choosing a Motor Design Speed".

[14] Holtz Joachim, Cunha Gilberto Da, Petry Norton, and Torri Paulo Jose "Control of Large Salient-Pole Synchronous Machines Using Synchronous optimal Pulsewidth Modulation", IEEE Transactions on Industrial Electronics, Vol. 62, No. 6, June 2015.

[15] Wu Bin, Pontt Jorge, Rodríguez Jose, Bernet Steffen, and Kouro Samir,"Current-Source Converter and Cycloconverter Topologies for IndustrialMedium-VoltageDrives",IEEE

Transactions on Industrial Electronics, Vol. 55, No. 7, July 2008.

[16] Bassham, Monterey Bobby A, "An Evaluation of Electric Motors for Ship Propulsion”, 2003-06.

[17] Dunne R, Morrell S. \& Lane G, "Design of The Biggest Mill In the World"

[18] Bos L. Vijfeijken Van De and Koponen J, "Insurability of Large Gearless Mill Drives".

[19] Combes M, Dirscher C, Rosch T,'Increasing availability through advanced Gearless Drive Technology", Siemens.

[20] Bopape Thulare, Klopper Hennie,"Design Review of Gearless Mill Drive: Mill System Analysis".

[21] Guerrero,Victor Pontt Jorge, Dixon Juan, and Rebolledo Jaime, "A Novel Noninvasive FailureDetection System for High-Power Converters Based on SCRs", IEEE Transactions on Industrial Electronics, Vol. 60, No. 2, February 2013.

[22] Apsley Judith and Williamson,Steve "Analysis of
Multiphase Induction Machines with winding faults", IEEE Transactions on Industry Applications, Vol. 42, No. 2, March/April 2006465.

[23] Soren B. Andersen, Ilmar F. Santos A, Axel Fuerst B, Lyngby, “ Applied Mathematical Modelling “. 39 (2015) 1941-1965.

[24] Williamson Steve and Smith Sandy, "Pulsating Torque and losses in Multiphase Induction Machines", IEEE Transactions on Industry Applications, Vol. 39, No. 4, July/August 2003.

[25] Tischler K. and Liepold H, "The Siemens $42 \mathrm{ft}$ Gearless Mill Drive, still an Evolutionary Design Approach?", Siemens.

[26] Guerrero Victor, Pontt Jorge, Dixon Juan, and Rebolledo Jaime, "A Novel Noninvasive FailureDetection System for High-Power Converters based on SCRS", IEEE Transactions on Industrial Electronics, Vol. 60, No. 2, February 2013.

[27] Mohammed Rezgar, Al Kababjie Khalil Maamoon, "Modeling and Simulation of Multi-Pulse Cycloconvereter-Fed AC Induction Motor and Study of Output Power Factor".

[28] Palani Kevin, Obispo San Luis, "Power Quality Analysis of A Three-Phase Cycloconverter Under Variable Operating Conditions", June 2010.

[29] Jokar Mohammad Amin, "Proposing New Technique for Designing AC Convertor", American Journal of Electrical and Electronic Engineering, 2017, Vol. 5, No. 3, 69-77.

[30] Luis Nieto, Gerencia C, Ahrens Markus, Dattwil Baden, "Gearless Mill Drive Protection Improvements and Its behavior at Minera Escondida Ltd”, 0197-2618/07 (C 2007 IEEE.

[31] Ekrem Cengelci, Prasad N, and Jamesw, "A New Modular Motor-Modular Inverter Concept for Medium-Voltage Adjustable-Speed-Drive Systems", IEEE Transactions on Industry Applications, Vol. 36, No. 3, May/June 2000.

[32] Gieras Jacek F, and Saari Juha "Performance Calculation For A High Speed Solid-Rotor Induction Motor", Article In IEEE Transactions on Industrial Electronics · June 2012.

[33] Siwakoti Yam P, Pham Ngoc Ha, "Power Electronics Converters-An Overview", Control of Power Electronic Converters and Systems, 2018.

[34] Melero M. G, Cano J. M, J. Norniella, F. Pedrayes, Cabanas M. F. Rojas C H, Alonso G, Aguado J. M, and Ardura P,"Electric Motors Monitoring: An Alternative to Increase The Efficiency of Ball Mills”, International Conference on Renewable Energies and Power Quality (ICREPQ'14), 8th to 10th April, 2014.

[35] Lezanma Pablo, Poum Josep, Thierry A. Meynard, Rodriguesze Jose, and Richardeau Frederic, "Survey 


\section{International Journal of Engineering Applied Sciences and Technology, 2021 \\ Vol. 6, Issue 4, ISSN No. 2455-2143, Pages 171-194 \\ Published Online August 2021 in IJEAST (http://www.ijeast.com)}

on Fault operation on Multilevel Inverter", IEEE Transactions on Industrial Electronics, Vol. 57, No. 7, July 2010.

[36] Ekrem Cengelci, Prasad N. Enjeti, and Jamesw. "A New Modular Motor-Modular Inverter Concept for Medium-Voltage Adjustable-Speed-Drive Systems", IEEE Transactions on Industry Applications, Vol. 36, No. 3, May/June 2000.

[37] Ramasamy Anbarasu, Osama,Mohamed Raphael Neumann, Ludwigsburg,"Direct Drive Segmented Generator", Patent No.: Us 9,660,493, May 23, 2017.

[38] Gupta Amit Kumar, Tripathi Anshuman, Ramasamy Anbarasu, Lubeck; Hadsten Ove Styhm,; Gil Lampong Opina, Karuppanan Yugarajan, Li Bing, Cao Shu Yu," Wind Turbine", Patent Us 8,957,536 B2 Feb. 17, 2015.

[39] Bjerknes Ole Johan, Breistein Hallvard,"Frequency Converter",Patent Us 8,587,141 B2 Nov. 19, 2013.

[40] Binesh Navid,"A Survey of Medium Voltage Drives, Specifications, and Practical Challenges", IEEE Houston Section, CED Seminar, February Houston Section.

[41] Sha Deshang, Qin Zian, Wu Dan, And Liao Xiaozhong,"A Digitally Controlled Three-Phase Cycloconverter type High Frequency AC Link Inverter Using space vector modulation", Journal of Power Electronics, Vol. 11, No. 1, January 2011

[42] An Hyunsung and Cha Hanju, "A New Start-Up Method For A Load Commutated Inverter for Large Synchronous Generator of Gas-Turbine", $J$ Electr Eng Technol.2018; 13(1): 201-210

[43] Brissette M,'Energy Savings and Technology Comparison Using Small Grinding Media", XXV International Mineral Processing Congress (Impc) 2010 Proceedings / Brisbane, Qld, Australia / 6 - 10 September 2010.

[44] Petereit Peter and Tischler Kurt,"Design and Dynamic Behavior of Large Ring Motors for Grinding Mills", Mining Technologies, SIEMENS SMMH 2012.

[45] Deepak Rashmy, Sandeep M P, "Harmonic Analysis \& Filter Design for A Novel Multilevel Inverter “,International Electrical Engineering Journal (IEEJ) Vol. 7 (2016) No.5, Pp. 2259-2265

[46] Hosoda Hiromi, Kodama Somiyasu, "Large PWM Inverters for Rolling Mills".

[47] Wagner Van, "Comparison of Medium Voltage And Low Voltage Adjustable Speed Drive Retrofits for Water and Wastewater Facilities", Schneider Electric, July 12, 2007.

[48] Jayaraman Meenakshi and Sreedevi,"Power Quality Improvement In a Cascaded Multilevel Inverter Interfaced Grid Connected System Using a
Modified Inductive-Capacitive-Inductive Filter with reduced power loss and Improved Harmonic attenuation", 10 November 2017.

[49] Doll Alex and Barratt Derek, "Choosing The Right Motors for your Mills", Procemin 2010, VII International Mineral Processing Seminar, Chile.

[50] Shattock, Nicholas,"High Frequency-Link Cycloconverters For Medium Voltage Grid Connection". PhD Thesis, University of Nottingham. Access from the University of Nottingham Repository 2014.

[51] Sudhoff S.D., . Zivi E. L, Collins T. D., "Start Up Perf'ormance of Load-Commutated Inverter Fed $S$ Ynchrounous Machine Drives", IEEE Transactions on Energy Conversion, Vol. 10, NO. 2, June 1995.

[52] Seggewiss George, Dai Jingya, \& Fanslow Mark, "Synchronous Motors on Grinding Mills" IEEE Industry Applications Magazine Nov-Dec 2015.

[53] Wu Bin, "High-Power Converters and AC Drives", IEEE Press, 2006 Edition.

[54] Krishnamoorthy Harish Sarma "Power Electronics Topologies With High Density Power Conversion and Galvanic Isolation For Utility Interface", May 2015.

[55] Derakhshanfar Mohammadreza, "Analysis of Different Topologies of Multilevel Inverters" 2012.

[56] Sathik M. Jagabar, Ramani K, "A Novel Approach of Multilevel Inverter With Reduced Power Electronics Devices", International Journal of Electronics and Communication Engineering, Vol:8, No:11, 2014.

[57] Adam G.P, Olimpo Anaya Lara and Mcdonald J. R., "Comparison Between Flying Capacitor and Modular Multilevel Inverter".

[58] Zhang Xiaohu,"Control Strategy of Cascaded HBridge, Multilevel Inverter With PV System as Separate DC Source" 2011.

[59] Ahmed Rokan Ali, Mekhilef S. \& Ping Hew Wooi "New Multilevel Inverter topology with minimum number of switches"Malaysia.

[60] Nordvall Andreas, Chalmers,"Multilevel Inverter Topology Survey Master of Science Thesis In Electric Power Engineering", Sweden, 2011.

[61] Leon M, Tolbert, Peng Fang Z, "Multilevel Converters for Large Electric Drives".

[62] Suresh K. Surya and M. Prasad Vishnu, "Analysis and Simulation of New Seven Level Inverter Topology".

[63] Dr Corzine Keith,"Operation And Design of Multilevel Inverters", June 2005.

[64] Alavi Omid, Viki Abbas Hooshmand and Shamlou Sadegh, "A Comparative Reliability Study of Three Fundamental Multilevel Inverters Using two 


\section{International Journal of Engineering Applied Sciences and Technology, 2021 \\ Vol. 6, Issue 4, ISSN No. 2455-2143, Pages 171-194 \\ Published Online August 2021 in IJEAST (http://www.ijeast.com)}

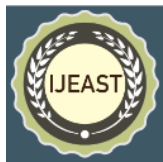

Different Approaches".

[65] Rodriguez J, Lai Jih Sheng, Peng Fang Zheng, "Multilevel Inverters: A Survey of Topologies, Controls and Applications," IEEE Trans. Ind.Electron, Vol.49, No.4, Pp.724-738, Aug.2002

[66] Malinowski Kouro S, M. Gopakumar K, Franquelo Pou J, Wu Bin, Rodriguez, J, Leon, Perez, "Recent Advances and Industrial Applications of Multilevel Converters,"IEEE Trans.Ind. Electron, Vol.57, No.8, Pp.2553-2580, Aug. 2010.

[67] Franquelo, L.G, Rodriguez, J. Leon, J. Kouro, S Portillo, R Prats, "The age of Multilevel Converters arrives," IEEE Ind. Electro. Magazine, Vol.2, No.2, Pp.28-39, June 2008.

[68] Zinoviev, Lopatkin G.S, "Evolution of Multilevel Voltage Source Inverters," In Conf. Rec 2008 Actual Problems of Electro. Instr. Eng., Vol.01, No., Pp.125-136, 23-25 Sept.2008.

[69] Babaei Ebrahim, Hosseini Seyed Hossein, "New Cascaded Multilevel Inverter Topology With Minimum Number of Switches," Energy Conversion and Management, Vol.50, Issue11, Nov. 2009.

[70] Kangarlu Farhadi, Babaei E, "Cross-Switched Multilevel Inverter: An Innovative Topology," IET Power Electro, Vol.6, No.4, Pp.642-651, April 2013.

[71] Kangarlu M.F, Babaei E, Sabahi M, "Cascaded Cross-Switched Multilevel Inverter In Symmetric and Asymmetric Conditions," IET Power Electron. , Vol.6, No.6, Pp.1041-1050, July 2013.

[72] Mokhberdoran A, Ajami A, "Symmetric and Asymmetric Design and Implementation of New Cascaded Multilevel Inverter Topology," IEEE Trans. Power Electron, vol.29, no.12, pp.67126724, Dec. 2014.

[73] Ye,Yuanmao Cheng, Liu Junfeng, Ding Kai, "A Step-Up Switched-Capacitor Multilevel Inverter with self-voltage balancing," IEEE Trans.Ind. Electron, Vol.61, No.12, Pp.6672-6680, Dec. 2014.

[74] Babaei E, Gowgani S.S,"Hybrid Multilevel Inverter Using switched capacitor units," IEEE Trans. Ind. Electronics, Vol.61, No.9, Pp.4614- 4621, Sept. 2014.

[75] Ajami Ali, Mokhberdoran A, Oskuee M.R, "A New Topology of Multilevel Voltage Source Inverter to Minimize the Number of Circuit Devices and Maximize the Number of output voltage Levels," $J$ Electr Eng Technol" Vol. 8, No. 6, Nov.2013.

[76] Ajami Ali, Oskuee M.R, Mokhberdoran A, Khosroshahi M. T. "Advanced Cascade Multilevel Converter With Reduction In Number of Components," J Electr Eng Technol" Vol. 9, No. 1, Jan.2014.

[77] Kouro S, Bernal R, Miranda H, Silva C.A,
Rodriguez J, "High-Performance Torque and Flux Control for Multilevel Inverter Fed Induction Motors," IEEE Trans.Power Electron., Vol.22, No.6, Pp.2116-2123, Nov. 2007.

[78] Mcgrath, B.P, Holmes, D.G, "Multicarrier PWM Strategies for Multilevel Inverters," IEEE Trans.Ind. Electron., Vol.49, No.4, Pp.858- 867, Aug. 2002.

[79] Aneesh, Gopinath A, Baiju M.R, "A Simple Space Vector PWM Generation Scheme For any General N-Level Inverter," IEEE Trans.Ind.Electron., Vol.56, No.5, Pp.1649-1656, May.2009.

[80] Li Czarkowski D, Liu Y, Pillay P, "Multilevel Selective Harmonic Elimination PWM Technique In Series-Connected Voltage Inverters," In Conf.Rec 1998 IEEE Industry Applications Conference, Vol.2, Pp.1454-1461.

[81] Shukla Ghosh, Joshi,, "Hysteresis Modulation of Multilevel Inverters," IEEE Trans.Power Electron., Vol.26, No.5, Pp.1396-1409, May 2011.

[82] Govindaraju C, Baskaran K, "Efficient Sequential Switching Hybrid-Modulation techniques for Cascaded Multilevel Inverters," IEEE Trans. Power Electron., Vol.26, No.6, Pp.1639-1648, June 2011.

[83] Ramani K, Rathinam A, Krishnan K, “An Enhanced Flying Capacitor Multilevel Inverter Fed Induction Motor Drive," ACEEE International Journal on Electrical and Power Eng., Vol.1,No.2,Pp.22-26,July 2010.

[84] Ramani K, Krishnan K,'High Performance of Sinusoidal Pulse Width Modulation Based Flying Capacitor Multilevel Inverter Fed Induction Motor Drive," International Journal of Computer Applications., Vol.1, No.24,Pp.116-121, Aug.2010.

[85] Nagarajan R, Saravanan M, "Performance Analysis of a Novel Reduced Switch Cascaded Multilevel Inverter ", Journal of Power Electronics., Vol.14,No.1,Pp.48-60,Jan. 2014.

[86] Senthil Kumar R, Surya Prakash R, Yokesh Kiran B, Sahana Anshuman, "Reduction and Elimination of Harmonics Using Power Active Harmonic Filter", IJRTE, July 2019.

[87] Yang Shaohua, Shao,Zhenguo Zheng Wendi, Chen Feixiong, "Mitigation Of Background Harmonics Effect on MMC Controller Based on a Novel Coordinate Transformation Technique", IEEE Access Nov 2019.

[88] Hossain Eklas, Tur Mehmat Rida, admanabhan Sanjivakumar P, "Analysis and Mitigation of Power Quality Issues In Distributed Generation Systems Using Custom Power Devices", USA April 2018

[89] Fahmi M I, Baafai U, Hazmi A, Nasution T H "Harmonic Reduction by Using Single-Tuned Passive Filter In Plastic Processing Industry", 10th International Conference Numerical Analysis In 
Engineering 2018.

[90] Das Jhuma, Mishra Ashutosh, "Reduction of Harmonics By Using Active and Passive Harmonics Filters", IJRASET, January 2018.

[91] Ismail Noramin Bin, "Improvement of Voltage Sags, Harmonic Distortion and Low Power Factor at Distribution System By Using Voltage Source Converter (Vsc) and Active Filter",January 2018.

[92] Miceli Rosario, Schettino Giuseppe and Viola Fabio,"A Novel Computational Approach for Harmonic, Mitigation In PV Systems With SinglePhase Five-Level CHBMI", Energies Aug 2018.

[93] Zare Firyz, Soltani Hamid, Dinesh Kumar, Davri Pooya, "Harmonic Emissions of Three-Phase Diode Rectifiers In Distribution Networks”, March 2017.

[94] Radhakrishnan Krishna,"Passive Filter Design and Optimisation of Harmonic Mitigation In Wind Power Plants", October 2016.

[95] Shaikh Rooh Ul Amin, Lashari Abdul Basit, Ansari Irfan, "Harmonics Analysis and Mitigation Using Passive Filters", January, 2015.

[96] Arikan O, Kocatepe C, Ucar G., Hacialiefendioglu , "Influence of Harmonics on Medium Voltage Distribution System: A Case Study for Residential Area", International Journal of Electrical and Computer Engineering, 2015.

[97] Eduful George, Jackson A., and Cole Joseph Ekow,"Harmonic Emission Limits and Selecting PCC Location Based on The Type of Distribution System",Proceedings of The World Congress on Engineering 2014, London. 